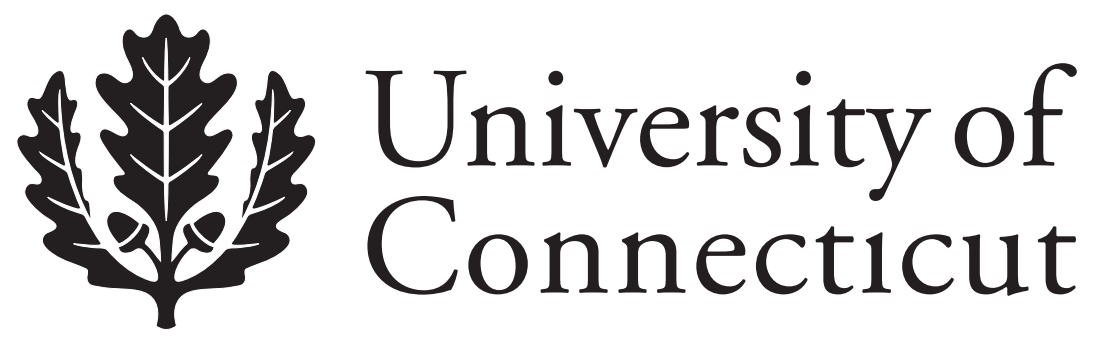

Department of Economics Working Paper Series

\title{
Low-Wage Labor Markets and the Power of Suggestion
}

Natalya Y. Shelkova

University of Connecticut

Working Paper 2008-33R

September 2008, revised December 2008

341 Mansfield Road, Unit 1063

Storrs, CT 06269-1063

Phone: (860) 486-3022

Fax: (860) 486-4463

http://www.econ.uconn.edu/

This working paper is indexed on RePEc, http://repec.org/ 


\begin{abstract}
Low-wage labor markets are traditionally viewed as competitive, and the possibility of strategic behavior by employers is dismissed. However, such behavior is not impossible. This paper investigates the possibility of tacit collusion by low-wage employers while setting wages. A game-theoretic explanation along the lines of the Folk theorem is offered, suggesting that a non-binding minimum wage may serve as a focal point for tacit collusion, proposing a symmetric solution to an infinitely played game of wage-setting. Several empirical techniques were employed in testing the hypothesis, including hurdle models of collusion. CPS monthly data is used for the years 1990-2005, covering the last four federal minimum wage increases. The likelihood of collusion at minimum wage is evaluated, as well as its dynamics during this period. The results generally support the collusion hypothesis and suggest that employers respond strategically to changes in minimum wage legislation while using the statutory minimum wage as a coordination tool in tacit collusion.
\end{abstract}

Journal of Economic Literature Classification: J31, J38, J42, L10

Keywords: minimum wage, low-wage markets, collusion, tacit collusion, focal points

I thank my adviser Christian Zimmermann for advice and support; professors Alpert, Couch, Dharmapala and Furtado for their discussions and comments; participants of the 2008 IRS Sundance Conference on Monopsony, particularly David Card, 2008 SOLE meetings, 10th IZA Summer School in Labor Economics, and UConn brownbag seminars for their input. All remaining mistakes are my own. 


\section{Introduction}

Minimum wage laws have been a hotly debated issue ever since their introduction in the early 20th century. Today their controversy has not diminished. Many empirical phenomena attributed to minimum wages still remain unexplained, triggering the development of new research contributing to already vast body of literature.

When analyzing the impact of the minimum wage, labor economists investigate its efficacy in raising earnings of low-wage workers, its effects on employment, and its overall distortional and welfare effects. When addressing these issues, researchers generally refer to the minimum wage as a price floor, the effects of which greatly depend on the competitive structure of underlying markets, as well as on whether the minimum wage is binding (relative to the competitive market wage). However, this traditional interpretation of the minimum wage role is not always successful in explaining a number of empirical phenomena. For instance, why do hikes in the minimum wage not necessarily reduce employment? Why do wages in low wage sectors grow more slowly when compared to the rest of the economy? Why are low-wage employers unwilling to raise wages even when unable to hire? Or why is the rate of job creation in the low-wage sector generally greater than the economy's average?

While keeping in mind these questions, this paper suggests to look at the role of the minimum wage from a new perspective. It proposes that a non-binding minimum wage can function as a focal point for tacit collusion by low-wage employers. A simple theoretical analysis of firms' wage choice in a dynamic setting shows that any wage ranging from the monopsony to the competitive level wage may lead to a stable (but socially inefficient) equilibrium if chosen symmetrically by employers. A minimum wage, when falling into this range of wages, can suggest such a symmetric solution, thus facilitating collusion.

If employers succesfully collude, the labor markets become de facto monopsonistic and Adam Smith was among the first researchers who mentioned this possibility. Manning (2003b:106) writes:

"...monopsony could also occur when there are many employers, but they collude in wage setting so that there are only a few effective employers in the labour market. Adam Smith strongly believed that employer collusion was a frequent outcome in labour markets: we rarely hear, it has been said, of the combinations of masters, though frequently of those of workmen. But, whoever imagines, upon this account, that masters rarely combine, is as ignorant of the world as of 
the subject. Masters are always and everywhere in a sort of tacit, but constant and uniform combination, not to raise the wages of labour above their actual rate. To violate this combination is everywhere a most unpopular action, and a sort of reproach to a master among his neighbours and equals. We seldom, indeed hear of this combination, because it is the usual, and one may say, the natural state of things, which nobody ever hears of (Smith, 1986: 169)."

The folk theorem, however, argues against the plausibility of collusion if employers are unable to coordinate. Schelling (1960) suggested that the collusion is still possible if there existed a focal point.

The idea that the minimum wage can be used by employers as a tool for coordination (the focal point) is also not entirely new. During the debates preceding the introduction of the Fair Labor Standards Act, John L. Lewis, representing the Congress of Industrial Organizations and the United Mine Workers of America, expressed concerns that the minimum 'fair' wage and the maximum hours that would be periodically set by the proposed FLS Board would tend to become the maximum wage and the maximum hours (Forsythe, 1939) ${ }^{1}$.

The fact that a salient focal point facilitates tacit collusion in potentially competitive markets is acknowledged in a number of recent interdisciplinary studies in finance and industrial organization. Such focal points could appear as a result of the government regulations, as in the case of statemandated ceilings on credit card interest rates (Knittel \& Stango, 2003); due to the industry standards, as in the case of requirements on stock price quotations in NASDAQ trades (Christie \& Schultz, 1994; Christie, Harris \& Schultz, 1994); or even due to the social norms (e.g., Harvey, 2006) . This paper expands the list of such interdisciplinary studies by applying the theory of tacit collusion at the focal point to low-wage labor markets.

The paper also contributes to the minimum wage literature by expanding the list of possible minimum wage effects. Empirically this is accomplished through the analysis of the well-documented minimum wage spike, part of which could be attributed to the employers' tacit collusion at the minimum wage.

Thus, the major effect of collusion is lowering of wages to the level of nonbinding minimum. The reader, however, should be cautioned that the goal of the paper is not to deterministically predict the extent to which wages are lowered as a result of collusion by low-wage employers facilitatated by the focal point. The major goal is rather to collect initial empirical evidence

\footnotetext{
${ }^{1}$ I thank Prof. Bill Alpert for pointing this out.
} 
of collusive behavior, to obtain indications of such behavior by analyzing its effects on the wage distribution.

I find that such indications are present. The number of potentially collusive observations at the minimum wage is responding to changes in the minimum wage level in the way consistent with theoreitcal predictions: collusion rises upon hikes at the minimum wage. At the same time, colluding employers are able to raise wages of workers who previously earned minimum wages, thus reducing the overall extent of collusion. I also obtain evidence that is consistent with the theory of facilitating factors: employers are more likely to collude when economic conditons worsen, when the costs of inputs increase and when the minimum wage hikes are anticipated. Collusion is likely in larger labor markets and when the real minimum wage erodes.

The paper is organized as follows. The next section surveys the existing labor literature which findings point towards validity of the collusion hypothesis. The third, theoretical, section brings together the theory of tacit collusion with the theory of focal points, applying its predictions to the low-wage labor markets. The fourth section explains the empirical strategy used in testing the hypothesis. Section five describes the data. Section six presents the results of empirical estimations, followed by the conclusion.

\section{Minimum Wage: Literature and Stylized Facts}

The minimum wage and its impact on labor markets has been extensively studied. Recent minimum wage research is predominantly empirical and usually looks at its employment effects, as reflected in a review by Brown (1999). The re-distributive role of the minimum wage is studied less frequently, as pointed out by Freeman: "Most of the analyses of the minimum wage focus on its unintended employment consequences. The goal of the minimum wage is not, of course, to reduce employment, but to redistribute earnings to low paid workers."

When the re-distributive impacts of the minimum wage are addressed, they are examined from the standpoint of whether the minimum wage increases earnings of low-wage workers (Meyer \& Wise, 1983), aids in combating poverty (Burkhauser et al., 1996), reduces wage inequality (Dickens et al., 2004; Teulings, 2003; DiNardo et al., 1996) or possibly affects the entire wage distribution (Neumark et al., 2004; Lee, 1999; Dickens et al., 1998).

Reconsidering the re-distributive efficacy of the minimum wage from a new angle poses a question, namely whether the minimum wage may reduce the wages of the low-paid (which could be realized if a minimum wage is non- 
binding and used by low-wage employers to coordinate their wage-setting). Stylized facts and selected prior research suggest that both coordination and non-bindedness of the minimum wage are possible, as evidenced by a large distributional spike at the minimum wage, wage compression, rising wage inequality and some other phenomena to be discussed.

\section{Minimum Wage Spike}

Perhaps the most important piece of evidence supporting the hypothesis of tacit collusion is the substantial clustering of wages around the statutory minimum - the so-called "minimum wage spike." Brown (1999, p.2143) summarizes:

"Among those who are employed, the distribution of $\ln ($ wage) tends to look bell-shaped with occasional spikes at round-dollar amounts. Often there is another spike, at the minimum wage, even when the minimum is not a round-dollar amount. Spikes at the minimum wage are stronger when the minimum wage is more binding; e.g. in wage distributions for teenagers rather than for all workers, and in years when the minimum wage has been raised rather than after several years of a constant nominal and eroding real minimum wage."

Wage information for a subset of retail and food industry hourly paid employees in October 1996 (an arbitrary choice), when the federal minimum wage level was $\$ 4.75$, shows that the minimum wage spike is, indeed, quite apparent (Figure 1).

Most common explanation of the minimum wage spike is the so-called 'forced truncation', suggesting that the minimum wage 'takes a bite' from the underlying wage distribution. Under this explanations some workers are believed to lose jobs (truncation), but some get their pay raised up to the minimum wage (censoring). This explanation, however, is challenged if one assumes that labor markets are competitive. If they were, profit maximizing employers should not have been able to sustain a mandatory pay increase, since wages that they were paying were already at worker's marginal productivity level. And, consequently, all workers whose wages were below the new minimum should be have been displaced and truncation, not censoring, should be observed.

The assumption of competitiveness should also translate into high empirical estimates of elasticity of employment with respect to minimum wage. However, these estimates are usually modest and applied only to subset of markets. Researchers report that a $10 \%$ hike in the minimum wage reduces teenage employment by about 1 to $6 \%$ and reduces employment of young 


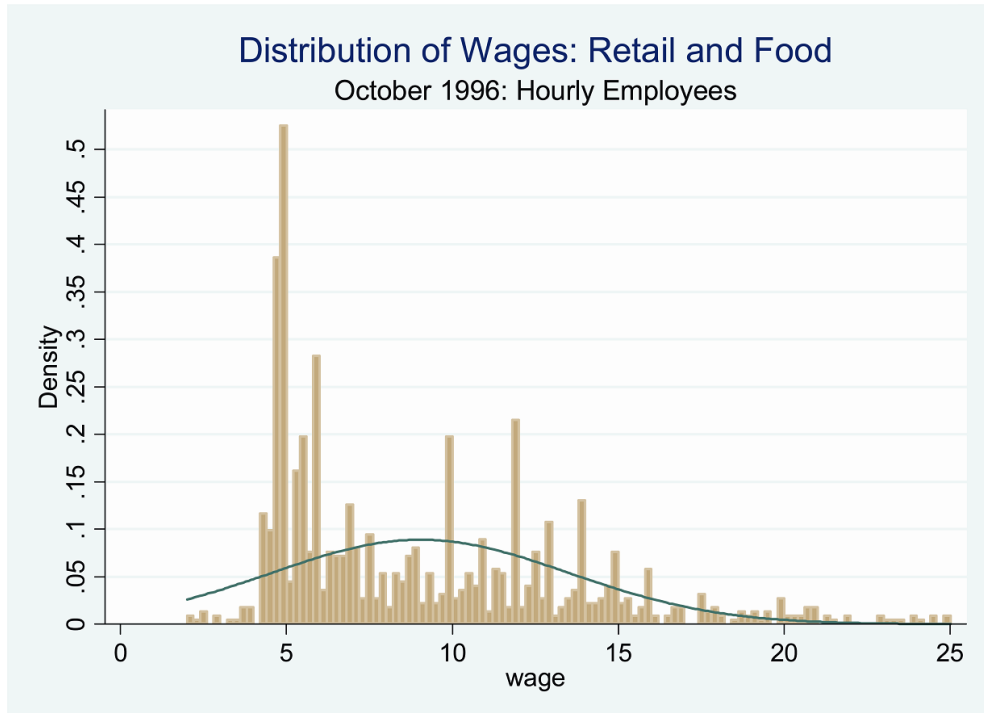

Figure 1: Minimum Wage Spike

adults by about $1 \%$ (Burkhauser et al., 1996). Almost no study surveyed by Brown (1999) reported a significant impact of a higher minimum wage on adult employment or total employment. Panel data studies also show that the employment elasticity estimates are small. For instance, Currie and Fallick (1996) using NLSY data estimate that only about $3 \%$ of youth are less likely to be employed a year after a minimum wage increase. Stewart (2004) using longitudinal data shows that the introduction of the national minimum wage in the UK did not have significant adverse effects on employment of any demographic group (adult and youth, men and women).

Thus, it raises a question whether there are any undercurrents in visibly competitive low-wage markets that would produce such elasticity estimates.

The theory of 'offsets' is another common explanation to the existence of the minimum wage spike. It suggests that competitive firms facing a higher minimum wage may re-optimize by adjusting non-wage compensation or increasing workers' marginal work-load without laying off workers (e.g., Wessels et al., 1980; Meyer \& Wise, 1983; Alpert, 1986). This is a plausible explanation, which could contribute to the appearance of the spike. In fact, the results show that even after correcting for possible collusion, the spike does not entirely disappear (see Figure 5), and the remaining spiking could well be attributed to the offsets. At the same time, the spike does 
not disappear completely even when minimum wage is eroded by inflation, which disagrees with the 'offsets' explanation.

Monopsony is another candidate for explaining the minimum wage spike. Though low-wage markets can hardly be viewed as structurally monopsonistic, they can become a de facto monopsony if successfully collude.

The recently developed theory of dynamic monopsony (Manning, 2003), based on the equilibrium search model of Burdett and Mortensen (1998), states that a monopsony-like equilibrium may arise even in visibly competitive markets due to the existence of search frictions. The theoretical model of dynamic monopsony, however, is unable to replicate the spike: "... the equilibrium wage distribution can have no mass points because it would then pay employers to deviate by paying an infinitesimally higher wage"(Manning, 2003a, p.327). Still, this theory does not contradict my proposition. Moreover, search frictions may further facilitate collusion by restricting already limited range of wage choices for unemployed workers.

Within the dynamic literature, Flinn (2003) was able to obtain a spike at the minimum wage in a search model with Nash bargaining. The model assumed that markets are competitive and the minimum wage poses as a binding constraint in a Nash-bargaining problem. Bargaining, however, could hardly be a characteristic of low-wage markets.

\section{Other Evidence}

The recent literature on employment effects of minimum wages suggests that the degree of competitiveness could be lower than conventionally believed. The estimates of employment elasticity with respect to the minimum wage also suggest that the recent increases in the minimum wage have not been binding.

A number of empirical studies report negative employment effects of the minimum wage, reporting reductions in employment of teenagers and youth. However, they also find that there are no effects on adults (Neumark and Wascher (1996, 2000), Burkhauser et al. (1996b, 2000)).

Card and Krueger (1995) conduct a series of studies where they argued that minimum wage increases of 1990's did not reduce employment, suggesting that affected markets are possibly monopsonistic. The absence of employment effects suggests that firms were able to raise wages for those earning the previous minimums, implying that workers were paid below the value of their marginal contributions in the first place. This could be explained if the minimum wage were a point of collusion, and its increase simply shifted the wage mass from one collusive equilibrium onto another. 


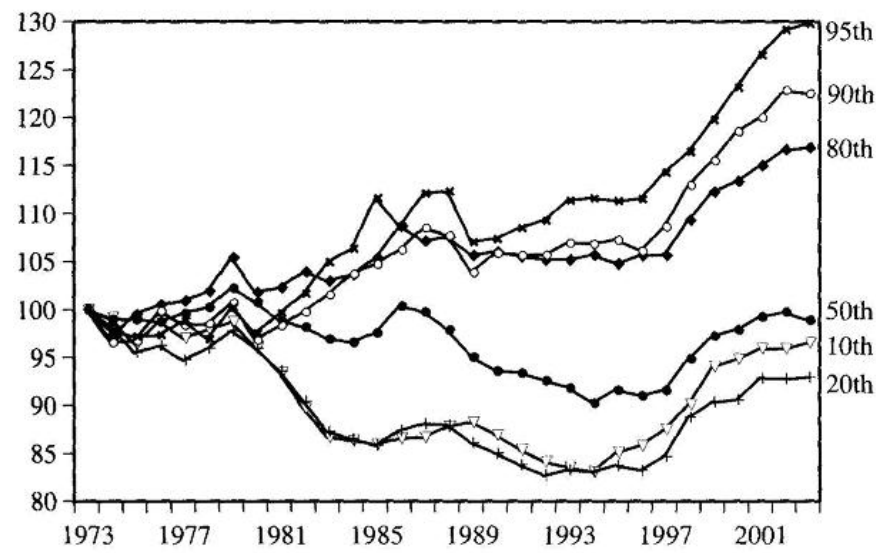

Figure 2: Changes in Real Wage for Different Percentiles*

*The State of Working America, 2004/2005

Overall, it is generally agreed that employment effects of the minimum wage are rather small, as summarized by Brown (1999), who rephrased a famous saying by Henry Kissinger: "...the debates over minimum wages were so spirited because the stakes were so low." Studies both before the 1980 s and in the 1990s showed that minimum wages have almost no effect on employment of adults and only some effect on employment of teenagers and youth.

Another interesting empirical phenomenon observed in the US labor markets during the past two decades is the increasing wage inequality between the low and the high paid workers (e.g., Freeman, 1996; Gottschalk, 1997; Lee, 1999). Statistics show that real wages of the tenth and twentieth percentiles of workers were either falling or stayed the same since the 1970s in relation to the steadily increasing pay of high-paid workers (see Figure 2).

Skill-biased technological change and declining manufacturing employment are often named as the driving forces behind the increasing disparity, as they shift the balance between the supply and the demand for the low-skilled. However, as some authors caution (e.g., Howell, Duncan, \& Harrison, 1998), the empirical evidence of such a major shift is thin. A nonbinding minimum wage serving as a reference point for wage-setting could be contributing to the widening gap.

The efficacy of the minimum wage in reducing/contributing to inequality has been addressed in several recent studies: Neumark et al. (2004), Machin 
et al. (2003), DiNardo et al. (1996), Lee (1999), Teulings (2003). The authors generally agree that minimum wages positively affect overall wage levels. However, they also note that, if the minimum wage is not raised frequently, its wage-lifting role may be diminished. Both Lee (1999) and Teulings (2003) find that the reduction in the real minimum wage increases wage inequality. For example, Teulings estimates that "...a 10\% reduction of the minimum wage causes the wage of a worker earning the minimum before the reduction to fall by $8 \%$ ".

The evidence of wage compression that accompanies increases in (introductions of) minimum wages can also be related to the tacit collusion hypothesis. For instance, Machin et al. (2003) when evaluating the introduction of the national minimum wage in the UK in 1999 showed that, while it increased wages of the low-paid in the home-care industry, it also caused greater compression at the bottom of the wage distribution.

To sum up, the evidence of the minimum wage spike, the low estimates of the elasticity of employment with respect to the minimum wage, the stagnating earnings of the low-paid and increasing wage inequality, and the wage compression all point in the direction that tacit collusion of low-wage employers at a non-binding minimum wage likely occurs.

\section{The Theory of Tacit Collusion at a Non-Binding Minimum Wage}

This section outlines a theory of collusion in labor markets by linking the standard Industrial Organization theory of tacit collusion with the Schelling's theory of focal points and applying it to the low-wage markets. A simple game-theoretic model - one of the possible variants of prisoner's dilemma (PD), illustrates the arrival of low-wage employers to the tacitly collusive equilibrium.

\section{Wage-Setting as a Coordination Game}

Suggesting that low-wage employers tacitly collude when setting wages assumes that they play a coordination game.

The assumption of wage-setting (not bargaining) is central for the coordination game to be possible. Wages that are observed in low-wage markets are often determined exclusively by employers, while employees have little influence. Since low-wage jobs are assumed to be homogenous, the pay is low, and the replacement of workers is relatively easy, firms have little incentives 
to invest in search, selection or negotiation of pay for each individual worker. Therefore, setting wages at some fixed level and waiting for vacancies to fill could be the best maximizing strategy (and transaction-cost-minimizing) for low-wage employers.

The fact that the low-wage jobs are homogenous and wage-bargaining is absent (at least in externally) creates an incentive for employers to coordinate wage-setting. If successful, such coordination may further reduce transaction costs and increase profits. Studies in industrial organization have many examples of such coordination in commodity markets: processed potato markets (Richards, Paterson, \& Acharya, 2001), retail gasoline markets (Borenstein \& Shepard, 1996), and timber sales (Baldwin, Marshall, \& Richard, 1997) among others.

Perhaps most relevant to this paper (and inspired by) is the study by Knittel and Stango (2003), who analyze the likelihood of coordination in credit cards' annual percentage rate setting by US banks in the 1980s. During the investigated period, credit cards characteristics were few, enough to assume homogeneity (APR was the main differentiating characteristic);

supply and demand sides of the market were represented by a large number of agents. These two conditions should had led to rather fierce competition among banks. However, the competition failed to emerge, as banks, soon after the adoption of the legislation which set APR limits (on state-by-state basis), learned that colluding on mandated rate levels was possible. This had led to folding of competition on APRs among banks and reflected through appearance of distributional spikes.

For the wage-setting to be identified as a coordination game, several other conditions should hold. These conditions include the symmetry of employers' preferences and beliefs, the multiplicity of potential equilibria, and ability of collusive equilibria to be self-supporting (Crawford \& Haller, 1990). The symmetry of preferences are self-explanatory: low-wage employers prefer low equilibrium wages over high, and their wage-setting practices are often alike so they can be easily inferred by one another. This addresses the symmetry. In the next section I discuss the multiplicity of potential equilibria and the sustainability of collusive equilibria.

\section{The Minimum Wage as a Focal Point Equilibrium in a Two-Firm Wage-Setting Game}

A simple two-firm model is offered next to illustrate the idea that tacit collusion at a non-binding minimum wage is a possible outcome of a wage- 
setting game played by low-wage employers ${ }^{2}$.

Proposition: If the minimum wage is non-binding, wage-setting employers will be drawn to set wages at the minimum wage.

Consider a market consisting of two identical firms $i$ and $j$ that operate in a perfectly competitive product market with product price $p$. Labor is the only production input, with the input requirement of one unit of labor per unit of output. Workers are perfectly substitutable. The marginal revenue product of labor is assumed constant. The market labor supply is an upward sloping function of the wage $S(w)$. In this environment, each firm sets the wage rate equal to the product price and will earn zero profits.

If firms compete in the labor market, a firm that pays a higher wage would attract the entire market labor force and would produce the entire market's output.

Now suppose that the two firms play a repeated wage-setting game in periods $t=0,1, T$. Let $\Pi_{i}\left(w_{i t}, w_{j t}\right)$ be a firm's $i$ profit at time $t$, and the wage it pays to its employees $w_{i t}$. Symmetric notation is used for firm $j$. Each firm maximizes the present discounted value of profits

$$
\sum_{t=1}^{T} \beta^{t} \Pi^{i}\left(w_{i t}, w_{j t}\right) .
$$

Both firms discount their one-period payoffs by the discount rate $\beta$.

At each date $t$ firms set wages, utilizing the knowledge of histories of wage-setting, i.e. the firm has a perfect recall of past wages with history $H_{i t}=\left[\left(w_{i 0}, w_{j 0}\right),\left(w_{i 1}, w_{j 1}\right), \ldots\left(w_{i T}, w_{j T}\right)\right]$, where $T$ is the current period.

In a finitely repeated game of wage-setting, this market is drawn to a Bertrand equilibrium. Thus, in equilibrium the wage rate is equal to a perfectly competitive wage.

Now, consider a wage-setting game in which the horizon is infinite $(T=$ $+\infty)$. In this case, the Bertrand equilibrium is also a stable solution, but it is no longer the only possible equilibrium.

Denote $w^{m}$ a monopsony wage, which maximizes monopsony profit

$$
\Pi^{m}=(p-w) S(w) .
$$

Suppose each firm follows a trigger strategy by setting the wage at the monopsony level $w^{m}$ if in every preceding period the competitor's wage was

\footnotetext{
${ }^{2}$ Here I closely follow Tirole (1988).
} 
$w^{m}$. By setting wages at this level, each firm earns half of the monopsony profits $\Pi^{m} / 2$. If a firm deviates and pays a higher wage $w>w^{m}$ in one of the periods, in this period it receives monopsony profit $\Pi^{m}$ and zero profit thereafter, since its rival sets the wage equal to the marginal revenue product of labor forever after the deviation from monopsony wage-setting, according to the trigger scenario.

Therefore, the trigger strategy will be an equilibrium if

$$
\frac{\Pi^{m}}{2}\left(1+\beta+\beta^{2}+\ldots\right) \geq \Pi^{m},
$$

which is equivalent to having $\beta>1 / 2$ (where 2 is the number of firms in the market). In other words, sharing the market and receiving half of the monopsony profits indefinitely is more attractive to both firms than competing for workers by offering higher wages, as long as the discount rate $\beta$ is sufficiently large. Notably, paying monopsony wage is a sustainable equilibrium even if no explicit coordination between the two firms is observed, thanks to the threat of zero profits.

The above model is a version of the Folk theorem for repeated games with application to the labor market. The theorem ascertains that the game may have multiple equilibrium solutions. That is, the equilibrium wage can be set anywhere between the monopsony wage $w^{m}$ and the competitive wage $w=p$, as long as it is set symmetrically.

Successful wage coordination of cost-minimizing firms can be problematic, especially if the number of firms, as well as the number of possible equilibria, is large. However, the existence of a focal point can help to solve this coordination problem.

The minimum wage as a focal point. Coordination in the wage-setting game and committing to some symmetric wage within the interval $w \subset$ $\left[w^{m}, p\right)$ is a difficult task for employers since the number of potential equilibria is large. As Tirole (1988:247) describes it:

"The supergame theory is, in a sense, too successful in explaining tacit collusion. The large set of equilibria is an embarrassment of the riches. Somehow the firms must coordinate on a 'focal equilibrium' in order for the equilibrium to remain attractive. How is this equilibrium chosen? A selection process often used in the literature makes the assumption that in a symmetric game the focal equilibrium is symmetric and the assumption that the focal equilibrium must be Pareto optimal from the viewpoint of the two firms (i.e., must yield a payoff on the frontier of attainable set of per-period profits)." 
The concept of a focal point equilibrium was first described by Thomas Schelling in his famous book "The Strategy of Conflict" (1960). The more recent literature on focal points includes Binmore and Samuelson (2006), Janssen (2001), Colman (1997), Crawford and Haller (1990), and some others. In his book, Schelling suggests that for parties with common interests in coordination and without opportunities to do so explicitly, it is logical to choose a reference point, which would stand out from the multiplicity of possible equilibria and would be attractive and value-maximizing for the majority of players.

The choice of a focal point depends greatly on the circumstances and the environment in which players operate. In Schelling's terms, players are scanning the environment looking for a key that makes collusion possible (1960, p.57):

"Finding the key, or rather finding a key - any key that is mutually recognized as the key - becomes the key - may depend on imagination more than on logic; it may depend on analogy, precedent, accidental arrangement, symmetry, aesthetic or geometric configuration, casuistic reasoning, and who the parties are and what they know about each other."

The successful solution of coordination puzzles depends on the availability and the number of focal points, on the number of players, and on the number of repetitions the game is played. The larger the number of focal points and/or the larger the number of players, the longer it takes for them to coordinate on a unique solution. If the game is played repeatedly, as in the dynamic game described above, it takes less effort to coordinate with each successive repetition.

Schelling's concept of a focal point can be directly related to the discussion of the minimum wage. A task of coordination for wage-setting employers evolves into finding a focal wage, or the Wage, in the range of possible equilibrium wages, which is acceptable and likely be chosen by other employers. A non-binding minimum wage can be used as such a focal point because of its salient location and its promise of the maximal payoffs to low-wage employers in the dynamic game of wage-setting.

\section{Empirical Implications}

Theory and preliminary analysis indicate that tacit collusion by low-wage employers is possible if they symmetrically decide to set wages at a nonbinding minimum. This section outlines the empirical implications of such 
behavior, including the effects of factors facilitating collusion. The following section presents quantitative checks of these implications.

Viewing the model presented in the previous section as a variant of the prisoners' dilemma, let me separate low-wage employers into cooperators and defectors. Cooperators choose to collude and secure their share of monopsony payoffs. Defectors, in turn, choose not to collude and receive monopsony profits in one of the periods, and reduced (or zero) profits thereafter, since defection triggers competition and reduces all firms' longrun profits. In the simple environment outlined in the previous section, a perfect collusion in every period will result. The real markets are certainly different at least in one additional dimension - the number of players.

Schelling (1973) describes a multiperson prisoners' dilemma (MPD) game that could be useful to the analysis in several ways. First, it allows for imperfect collusion, a situation when some employers cooperate while others defect, an attractive feature most likely found in real world markets. Second, Schelling's graphical model can be used in analysis of comparative statics.

According to Schelling, the imperfect collusion is possible due to the presence of continuous externality which assumes that one player's decision to collude increases payoffs of non-colluders. The larger the number of colluders, the higher the payoff of a defector. A simple graphical illustration of an MPD is presented in Figure 3. It depicts representative firm's instantaneous payoff from colluding (lines $C$ ) and defecting (lines $D$ ) against the number of colluding firms on the market. The total number of firms is $n$. In Schelling's model the right vertical intercept of $D$ at zero indicates zero payoffs in case when all firms compete (competitive equilibrium). The left vertical intercept of $C$ indicates payoffs when all firms collude (cooperative equilibrium). As evident from the graph, the defectors' payoff is higher at all collusion levels, inevitably leading to the competitive outcome. If, however, there existed a fraction of 'devoted' colluders of size $k$, the partially collusive equilibrium becomes possible, with payoff $Q>0$ to defectors and zero payoffs to colluders. This parameter $k$ represents the minimum size of a viable coalition.

The possibility of imperfect collusive outcome is rather relevant in this case since empirical wage distributions are non-degenerate: neither perfect competition, nor perfect collusion is observed. I use this assumption in order to identify potentially collusive wage observations by comparing wages at the minimum (collusive) to wages above the minimum (non-collusive). However, one should be warned, as the Schelling's model suggests, that in case of imperfect collusion wages paid by defectors will still be lower than perfectly competitive wages, since defection is defined as a small deviation from the 


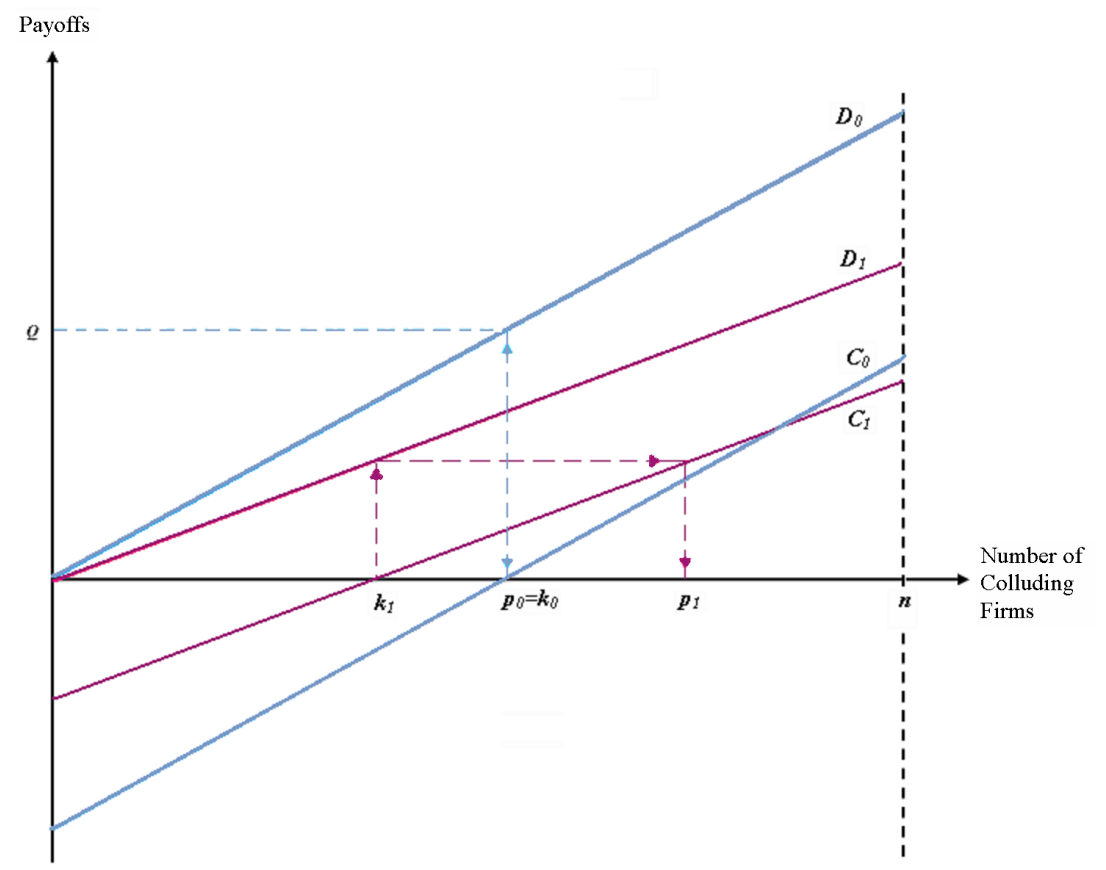

Figure 3: Effect of Higher Cost on Likelihood of Collusion

collusive level pay.

Schelling's MPD and its graphical representation can be used in order to illustrate the effects of facilitating factors on the likelihood of collusion. According to the collusion theory, one of the important facilitating factors is the cost of inputs (in our case, the cost of other inputs, since labor is also an input). Increasing input costs by reducing the benefits of defection increases the attractiveness of collusion.

Denote $r$ as the costs of inputs (other than labor) used in production. Then, using the formulas from the previous section, the instantaneous payoff to a defector is $\Pi^{m}=(p-r-w) S(w)$, while the payoff to a cooperator is $\frac{\Pi^{m}}{n}$ (assuming that a deviation from the monopsony wage is infinitesimally small). A simple algebra shows that as $r$ rises, the payoff to a defector falls by $S(w)$, and the payoff to a colluder (when all collude) falls by $\frac{S(w)}{n}$. Graphically, it changes the right vertical intercepts for both curves $D$ and $C$, with a larger vertical move for $C$ (prior $D_{0}$ and $C_{0}$ are now $D_{1}$ and $C_{1}$ ).

A rising $r$ has important implications that can be traced graphically. 
First, its reduces the difference between instantaneous payoffs for cooperators and defectors. Second, the higher cost makes initial collusion easier the minimum size of the viable coalition is now at $k_{1}$ (compared to prior $k_{0}$ ). As a result, the number of colluding firms increases from $p_{0}$ to $p_{1}$. In our example, the initial number of colluders coincided with the minimum viable coalition $\left(p_{0}=k_{0}\right)$, but the final number of colluders exceeds the minimum viable coalition $\left(p_{1}>k_{1}\right)$. Though, the result generally holds for other initial settings.

This example illustrates how a change in the input costs can affect the likelihood of collusion, the effects of other facilitating factors can be analyzed similarly.

Overall, collusion at the minimum wage should have the following empirical general implications, with some mentioned in the first part of the paper:

- Wage clustering at the minimum. If a focal point facilitates collusion, extensive clustering of observations at the minimum wage should be observed. This is the minimum wage spike that was a main motivator for this paper. The extent of the clustering should be responsive to changes in the minimum wage levels.

- Lower wages. If employers collude at a non-binding minimum wage, it reduces wages of affected workers. All things equal, collusion should lead to lower wages in localities with lower minimums than in localities with higher minimums. As a result, when minimum wage is raised, wages of affected workers increase.

- Increasing wages when minimum wage is raised without negative employment effects. As was already discussed, an increase in the minimum wage from one non-binding level to another non-binding level should increase wages as it re-distributes surplus from employers to workers without effects on employment.

- Profitability and market entry. Assuming competitive product markets, which is arguably the case for industries with low wages, high and persistent profits "...not accounted for by cost or product quality advantages" could indicate collusion in labor markets(e.g., Porter, 2005). This, in turn, would lead to market entry and higher than average rate of job creation in the industry .

Though not previously tied to collusion, most of these general empirical implications consistent with predictions of the collusion theory are well 
documented in the labor literature. Perhaps, the exception would be the last implication, testing which could be an interesting new avenue for future research.

In addition to the general implications, the collusion at the minimum wage should be responding to changes in the following facilitating factors (similar to Knittel \& Stango, 2003):

- Changes in the minimum wage. A higher but non-binding minimum wage should increase employers' propensity to collude since deviation (i.e. paying higher wages) becomes relatively less attractive. A new minimum wage level can also provide a signal to employers about the start of new game and as experimental IO literature suggests cooperative behavior is more likely during initial stages of multi-period games. At the same time, a higher minimum will also increase wages of the low-paid, thus reducing the overall negative effect of collusion on wages. An eroding real minimum wage, however, should reduce collusion as deviation becomes more attractive.

- Costs of other inputs. As was discussed above, higher costs of other inputs facilitate collusion.

- Anticipated hikes in the minimum wage. An announcement of a future increase in the minimum wage should have similar effects as increasing costs of other inputs. Thus, one should expect greater collusion prior to actual changes in the level of minimum wage as employers re-optimize and take advantage of the previous lower focal point.

- Number of firms in the market. Tacit collusion is easier to sustain when the number of employers on the market is small ceteris paribus, since coordination is trivially simpler.

- Firm size may have either a positive or a negative impact on the propensity to collude. Larger firms enjoying the scale economies have relatively smaller costs, thus giving them more room for defection. At the same time, larger firms have longer 'lives', making them more interested in the cooperative outcome of the wage-setting game. The supergame argument also applies if one views larger firms as more visible market players, which wage-setting practices are easily discovered (and punished) by competitors.

- Favorable (product and labor) demand conditions. Collusion is more 


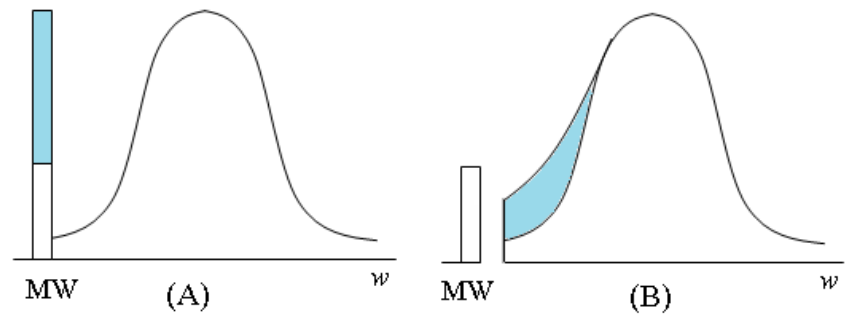

Figure 4: Wage Distribution and Collusive Observations

difficult to sustain in periods of high demand due to increased incentives to deviate (Rotemberg \& Saloner, 1986).

Though, it would be helpful to test every listed implication, the available data does not allow to do so. In the next section I define alternative measures of collusion and outline strategies for testing the empirical implications.

\section{Empirical Strategy}

The major effect of collusion at a non-binding minimum wage is the reduction of otherwise higher wages down to the minimum. Empirically it observed in the form of excessive clustering the minimum wage spike (Panel A, Figure 4). Assessing the fraction of minimum wage observations that are collusive is one way of measuring the effect of collusion. I further refer to this measure as the 'effect' measure, the formal expression for which is provided further in (8).

However, prior to observing this effect, there was an act of collusion as the process of replacing competitive wages with minimum wages. Thus, an alternative measure of collusion can be formulated as a fraction of collusive wages within the pool of otherwise non-binding wages, later referred to as the 'cause' measure. Panel B of Figure 4 illustrates this measure as a ratio of shaded area within the entire area of the wage distribution above the minimum wage, with formal expression given further in (9).

While I estimate both measures of collusion, I built upon Knittel and Stango (2003) who estimate hurdle models of collusion (also known as pTobit) to evaluate the propensity to collude by employers with competitive level wages above the minimum, i.e. the 'cause' measure. I also expand 
their empirical method (mainly due to data issues) by adding truncated regressions to evaluate both the cause and the effect measures, and add probit models to test the theory of facilitating factors.

When estimating p-Tobit models two requirements should be met. First, the distribution requires clear-cut censoring. Second, it is assumed that the rest of the distribution is not contaminated by processes generating the spike, which is necessary if one needs to compare spike and non-spike observations. The first requirement is not met since empirical wage distributions have wage observations below the minimum wage due to non-compliance or subminimum wage provisions. Second, I argue that the wage observations near the minimum wage (which acts as a focal point for tacit collusion) are very likely affected, i.e. adjacent wages are also lower than the competitive level wages if the game of wage-setting played by employers is to arrive at the Nash equilibrium. It has been also noted in the literature (e.g., Flinn 2003 \& others)) that extensive clustering exists not only at the minimum wage, but also at nearby round amounts, that could be also examples of focal points (though obviously inspired by the mail focal point - the mandated minimum wage).

A variant of p-Tobit used by Knittel and Stango can still estimate the extent of collusion relatively precisely, if one has a comparison group of unaffected markets. The model then can identify the collusive observations by comparing them against the upper tail of own distribution as well as against the desired comparison group. However, it is very difficult to find such a group of unaffected, but relevant labor markets in the US, since most of the US industries are required to comply with the minimum wage laws. Moreover, even the exempt markets, such as the agricultural industry exhibits sizeable spike (e.g., Moertti \& Perloff, 2000) at the minimum wage, which in my view questions the degree to which these markets are unaffected.

These limitations have lead to a deviation from the original empirical approach of Knittel and Stango. The major part in discerning collusive minimum wage observations is obtaining the correct wage schedule. Assuming that collusion is imperfect (as in MPD model discussed above), the existing non-minimum-wage observations can provide enough information in order to estimate the 'correct' wage equation. I refer to this assumption when estimating both a reduced variant of p-Tobit model and truncated regressions. It is useful, however, to start the discussion of empirics with the formulation of p-Tobit since it outlines the basic maximum likelihood function used in both cases. 


\section{Basic P-Tobit Model}

The p-Tobit can help to evaluate the likelihood of collusion at a non-binding minimum wage by the means of maximum likelihood. It is built upon Tobit with an extra estimated probability parameter $p$ that denotes the fraction of minimum wage observations for which minimum wage is non-binding.

Next, I define a likelihood function that is used to estimate the parameter $p$, following closely the specification by Knittel and Stango (2003).

The reduced form wage equation (the latent wage) in the absence of collusion and minimum wage restriction is:

$$
w_{i t}^{*}=X_{i t} \beta+\mu_{s}+\eta_{t}+e_{i t},
$$

where:

$X_{i t}$ - is a set of worker characteristics;

$\mu_{s}-$ is a set of state fixed effects;

$\eta_{t}$ - is a set of time-period fixed effects;

and $e_{i t}-$ is an error term, $N\left(0, \sigma^{2}\right)$.

The list of variables included in the vector $X$ of worker characteristics is given in Appendix 2.

A minimum wage censors the wage distribution according to the following schedule:

$$
w_{i t}= \begin{cases}w_{i t}^{*} & \text { if } w^{*}>M_{s t} \\ M_{s t} & \text { if } w^{*} \leq M_{s t}\end{cases}
$$

where $M_{s t}$ - is a minimum wage in state $s$ at time $t$. Note the censoring, not the truncation, allowing to bring wages below the minimum up to the minimum. Thus, the probability of observing wage that is equal to the minimum wage is:

$$
\begin{gathered}
P\left(w_{i t}=M_{s t}\right)=P\left(w_{i t}^{*} \leq M_{s t}\right)=P\left(\varepsilon_{i t} \leq\left(M_{s t}-X_{i t} \beta-\mu_{s}-\eta_{t}\right)\right)= \\
=\Phi\left(\frac{M_{s t}-X_{i t} \beta-\mu_{s}-\eta_{t}}{\sigma}\right) .
\end{gathered}
$$

With allowance for censoring, the likelihood function is a simple Tobit:

$$
L=\prod_{w_{i t}=M_{s t}} \Phi\left(\frac{M_{s t}-X_{i t} \beta-\mu_{s}-\eta_{t}}{\sigma}\right) \prod_{w_{i t}>M_{s t}} \frac{1}{\sigma} \phi\left(\frac{X_{i t} \beta+\mu_{s}+\eta_{t}-M_{s t}}{\sigma}\right) .
$$


Introducing an indicator of collusion:

$$
c_{i t}= \begin{cases}1 & \text { if an employer colludes; } \\ 0 & \text { otherwise }\end{cases}
$$

With collusion, the observed wage schedule becomes:

$$
w_{i t}= \begin{cases}w_{i t}^{*} & \text { if } w_{i t}^{*}>M_{s t} \text { and } c_{i t}=0 \\ M_{s t} & \text { if } w_{i t}^{*}=M_{s t} \text { and } c_{i t}=0 \\ M_{s t} & \text { if } w_{i t}^{*}>M_{s t} \text { and } c_{i t}=1\end{cases}
$$

The likelihood function becomes:

$$
\begin{array}{r}
L=\prod_{w_{i t}=M_{s t}}\left[\Phi\left(\frac{M_{s t}-X_{i t} \beta-\mu_{s}-\eta_{t}}{\sigma}\right)+p \Phi\left(\frac{X_{i t} \beta+\mu_{s}+\eta_{t}-M_{s t}}{\sigma}\right)\right] \\
\prod_{w_{i t}>M_{s t}}(1-p) \frac{1}{\sigma} \phi\left(\frac{X_{i t} \beta+\mu_{s}+\eta_{t}-w_{i t}}{\sigma}\right),
\end{array}
$$

which is the basic p-Tobit, in which $p$ measures the conditional probability of collusion when minimum wage is non-binding. It represents a fraction of wage observations for which the latent wage is above the minimum, but the actual wage is the minimum.

The evaluation of the likelihood of collusion by means of p-Tobit would benefit from inclusion of a comparison group of unaffected/non-covered markets. If the indicator of coverage is:

$$
I_{i t}^{c o v}= \begin{cases}1 & \text { if a worker employed in covered sector; } \\ 0 & \text { otherwise }\end{cases}
$$

then, the observed wage schedule becomes:

$$
w_{i t}= \begin{cases}w_{i t}^{*} & \text { if } w_{i t}^{*}>M_{s t}, I_{i t}=1 \text { and } c_{i t}=0 ; \\ w_{i t}^{*} & \text { if } I_{i t}=0 \text { and } c_{i t}=0 ; \\ M_{s t} & \text { if } w_{i t}^{*}=M_{s t} \text { for } \forall I_{i t} ; \\ M_{s t} & \text { if } w_{i t}^{*}>M_{s t} \text { and } c_{i t}=1 .\end{cases}
$$

Incorporating the latter into the likelihood function produces:

$$
\begin{aligned}
L= & \prod_{I^{\text {cov }}=1}\left[\prod_{w_{i t}=M_{s t}}\left(\Phi\left(\frac{M_{s t}-X_{i t} \beta-\mu_{s}-\eta_{t}}{\sigma}\right)+p \Phi\left(\frac{X_{i t} \beta+\mu_{s}+\eta_{t}-M_{s t}}{\sigma}\right)\right)\right. \\
& \left.\prod_{w_{i t}>M_{s t}}(1-p) \frac{1}{\sigma} \phi\left(\frac{X_{i t} \beta+\mu_{s}+\eta_{t}-w_{i t}}{\sigma}\right)\right] \prod_{I^{c o v}=0} \frac{1}{\sigma} \phi\left(\frac{X_{i t} \beta+\mu_{s}+\eta_{t}-w_{i t}}{\sigma}\right)
\end{aligned}
$$




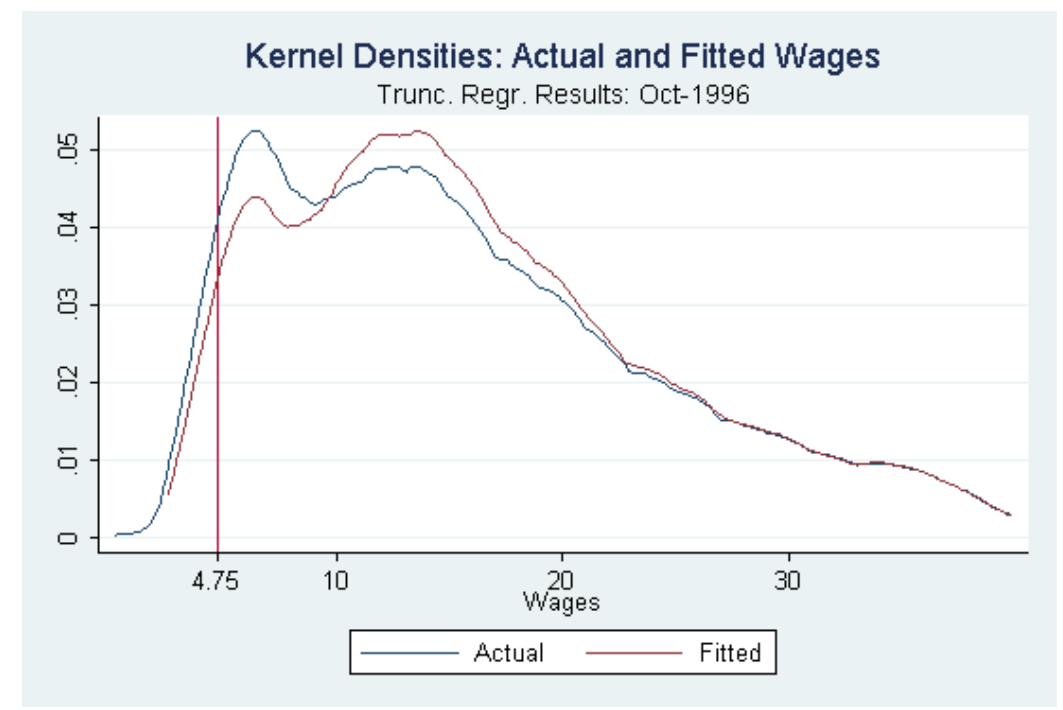

Figure 5: Actual and Predicted Wages

Again, in equation (7) $p$ stands for the conditional probability of tacit collusion when the minimum wage is non-binding in the covered sector. It assumes that the non-covered sector is unaffected by collusion.

However, as was discussed before, it is difficult to locate an unaffected market in the US. Thus, I estimate the first variant of p-Tobit without division by coverage as in $(6)^{3}$.

\section{Alternative Estimation Technique: Truncation}

One of the problems associated with empirical wage distributions in the low-wage sectors supposedly affected by collusion at the non-binding minimum wage is the likely contamination of nearby wages. Wage histograms show that the spiking occurs not only at the minimum wage but within a larger interval surrounding it (see Figures 1,5). This spiking can corrupt the accuracy of estimates obtained in p-Tobit regressions that analyzes the minimum wage spike exclusively, thus potentially creating a downward bias.

\footnotetext{
${ }^{3}$ In the previous version of the paper I have attempted to circumvent the problem by splitting the sample into two groups and censor only one of them, estimating the variant of p-Tobit specified in (7). This utilizied information about the actual number of belowthe-minimum wage observations. The obtained then estimates of $p$ were actually higher than currently reported.
} 
On the positive side, there is enough of non-minimum wage information, that combined with available computing power can estimate wage equations by means of maximum likelihood rather accurately, which then can be used to predict wages of those currently earning the minimum.

Thus, I estimate a series of ML truncated regressions (also known as twolimite Tobit) in order to reduce potential contamination and to obtain a wage sample that is closer to the competitive. I then use the modified sample in order to estimate a wage equation to predict wages of those currently earning the minimum. This allows to obtain the 'effect' measure of collusion:

$$
\text { Effect Measure }_{t}=\frac{\sum_{i=1}^{N} I\left(\left(w_{i t}=M_{i t}\right) \cap\left(\hat{\hat{w}}_{i t}>M_{i t}\right)\right)}{\sum_{i=1}^{N} I\left(w_{i t}=M_{i t}\right)} .
$$

In the equation (8) $\hat{w}_{i t}$ is the predicted wage based on estimates of an ML truncated regression, the likelohood function for which is nested within the previously specified p-Tobit model (e.g., the part of the expression (5 corresponding to data points $w_{i t}>M_{i t}$ ).

In order to obtain the 'corrected' wage sample I initially truncate the wage data (restricted to hourly paid workers) at the 25 th percentile for each of the analyzed periods ${ }^{4}$ and estimate the maximum likelihood truncated regression (also known as two-limit Tobit). Procedure of this sort invokes a response variable based selection $(\sim$ selection on dependent variable, Wooldridge 2002:558). The maximum likelihood method explicitly accounts for this type of selection since it estimates wage equation conditional on the set of regressors $X$ as well as on the specified selection rule: $c_{1}<w<c_{2}(\infty)$ (where $c_{1}$ is the specified cutoff limit). The resulting conditional expectation of $w$ depends not only on $X^{\prime} \beta$, but also on the inverse mills ratio that takes into account the selection rule. Thus, one is able to obtain the set of estimates that is not biased by the selection.

After estimating the ML truncated regressions using the initial selection rule, I use its results to predict wages of workers who earn wages within the 50-cent range from the original cutoff point. If the predictions are significantly lower (in the statistical sense) than actual wages, the actuals are substituted by the predictions. I then proceed to establish a new cutoff point, down an additional 50 cents, and estimate the ML truncated regression using this larger set of the data (utilizing the imputated wages). I repeat this procedure until the wages below the minimum are reached. Figure 5 illustrates the extent to which the original wage sample was modified when

\footnotetext{
${ }^{4}$ Examination of data on wage growth by percentiles, an illustration of which is provided in Figure 2, suggests that the lower percentiles of wage distribution are most likely affected.
} 
$80 \%$ lower confidence interval rule is applied (October 1996, an arbitrary choice).

As truncated regressions allows to determine the number of minimum wage workers whose wages are significantly below the predictions, a 'cause' measure of collusion comparable to the original p-Tobit's $p$ can be evaluated according to the formula:

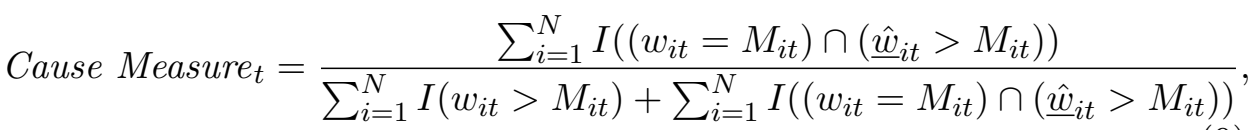

where $N$ is the number of workers and $\underline{\hat{w}}_{i t}$ is the lower confidence interval for the wage prediction.

Although this 'cause' measure of collusion is comparable to the p-Tobit, one should expect the divergence in the actual estimates, since the models utilize different sets of information.

\section{Is it Collusion? Probit Model}

The results of truncated regressions, by providing an indication whether a minimum wage observation could be a result of collusive wage-setting, were also used in testing the theory of facilitating factors. The approach I take is somewhat similar to the analysis of the second hurdle in the 'double-hurdle' model of Cragg (1971), in which the contribution of various factors to the probability of crossing the 'hurdle' are evaluated.

The probit model estimations are based on the following equation:

$$
y_{i t}=Z_{i t} \gamma+\nu_{i t}
$$

where $y_{i t}$ is the indicator of collusion; $Z_{i t}$ is the vector of facilitating factors; and $\nu_{i t}$ is an error term, $N\left(0, \sigma_{\nu}^{2}\right)$.

The following schedule describes values taken by the dependent variable and the selection of observations into the probit estimations:

$$
y_{i t}= \begin{cases}1 & \text { if } \hat{w}_{i t}>w_{i t} \& w_{i t}=M_{i t} \\ 0 & \text { if } w_{i t}>M_{i t} \& w_{i t}<\max _{i, t}\left\{\hat{w}_{i t} \cdot I\left(y_{i t}=1\right)\right\}\end{cases}
$$

where $\hat{w}_{i t}$ is the predicted wage based on truncated regression results. The choice of observations is also illustrated in Figure 6, where the shaded area in the center segment represents the potential location of collusive minimum wage observations. Thus, the probit regression by comparing the 


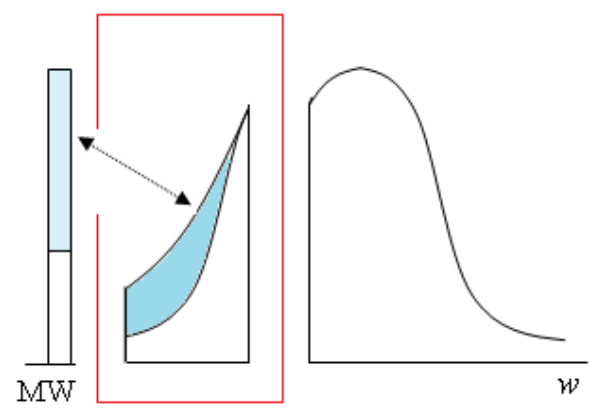

Figure 6: Choice of Observations for Probit Regression

non-collusive observations to the collusive observations with equal predicted wage values, allows to identify what factors are contributing to collusion, i.e. tests the theory of facilitating factors.

\section{Data}

Data used in the paper is monthly Current Population Survey earnings extracts prepared by the NBER (MORG files). Variables included in the MORG extracts reflect workers' earnings, industry, occupation, education, unionization, as well as some background variables: age, sex, race, ethnicity, geographic location, etc. Sixteen years of CPS were used in the estimations, 1990 through 2005, a period that covers the last four federal minimum wage increases and indicates extensive variation in states' own minimum wage levels.

State and the federal minimum wage data used is given in Appendix 1 (US Department of Labor data on minimum wages combined with annual surveys of states' labor legislation published in Monthly Labor Review annually). Necessary for testing the theory of facilitating factors, additional information merged with the original sets: state level monthly unemployment rates (source: US DOL); monthly CPI indices in order to calculate real minimum wages and monthly prime interest rates (source: St.Louis Fed).

Hourly paid employees' data was used only since the study needed the exact values of hourly wages, and minimum wages in most cases during the investigated period had not been a round amount. Calculation of hourly wages based on weekly earnings data would not have provided the necessary 
information. Hourly employees are also the primary category of interest since hourly employees are the directly affected group by the minimum wage legislation.

Minor data cleaning was performed. Workers' records satisfying the following conditions were excluded: reported as being a member of the fulltime labor force, but no work hours; weekly earnings were less than $\$ 100$; hourly wages lower than $\$ 1$. All workers older than 75 years were excluded.

\section{$6 \quad$ Estimation and Results}

\section{The Extent of Collusion: Truncated Regressions and P-Tobit}

Tacitly collusive behavior is difficult to detect, especially in visibly competitive markets such as the low-wage labor markets, where the number of workers and employers is large. Thus, one need to have several pieces of evidence pointing towards existence of collusive trends.

The major effect of collusion at a non-binding minimum wage serving as a focal point is the reduction of wages to the minimum from otherwise higher levels. The results of both truncated regressions and p-Tobit indicate that it exists, it is persistent, and exhibits cyclicity visibly related to shifts in minimum wage levels.

A couple of comments on estimation procedure. The consecutive estimation of truncated regressions, as it allowed to evaluate the initial 'cause' and 'effect' measure of collusion, also prepared data for p-Tobit estimation. Truncated regression models were estimated on average 14 times for each of the 192 months of data (16 years). Wages at the point of initial truncation (at 25th percentile of hourly wage distribution) ranged from $\$ 8.50$ in 1990 to $\$ 12.50$ in 2005 . Wages of workers within the lowest quartile and earning less than the lower $80 \%$ confidence interval of its forecast were imputed $^{5}$. As a check of robustness, I run a series of ML truncated re-

\footnotetext{
${ }^{5}$ The computation of confidence intervals was done using the standard error of the forecast, which is significantly larger than the more common standard error of the prediction. Since I impute wages for workers originally not in the estimation sample, using the forecast SE is more appropriate. To illustrate the difference between the two, consider the results of regression for January 1995 truncated from the left at $\$ 9$. The average log-wage for the interval $\$ 8.50-8.99$ is equal 2.172 , with the average forecasted log-wage is 2.396 . The average standard error of the prediction is 0.071 , which gives the lower $99 \%$ CI for the predicted log-wage equal to 2.213 . The average standard error of the forecast is 0.433 (six times larger than the prediction SE), which gives the lower $80 \%$ CI of the forecast equal to 1.841 Using the more stringent criteria for the imputations allows to flag wages of workers only significantly smaller than their predictions as potentially collusive with a
} 
gressions by restricting the data to the second quartile of hourly employees only. The results were similar, and in a number of instances the obtained earnings function coefficients predicted even higher wages. All estimates are heteroscedasticity-corrected, as tests suggested that this problem is present in the data.

The monthly estimates of potential collusion based on the ML truncation regressions are presented in Appendix 3, which includes two sets of tables: one for the states that follow the federal minimum wage regulation consistently throughout the estimation period, and the complementary set of states with own minimum wage laws (see the list of states in Appendix $1)$.

As collusion theory predicts, substantial clustering of wages at the focal point is observed. Figure 7 shows the fractions of minimum wage observations ( +50 cents) within the lower quartile of hourly wages - the relative hight of the minimum wage spike. It is apparent from the graph that the clustering increases following the hikes in the minimum wage in 1990-1991 and 1996-1997, with the federal MW states being more affected. The next question is: how many of these observations are actually collusive?

Figure 8 presents the results on the cause measure of collusion ${ }^{6}$. As the pattern of change in this measure is rather similar to the spike measure, it suggests that response of employers to the changes in the minimum is consistent and somewhat deterministic.

This result provides initial empirical evidence on prediction that a higher, but non-binding, minimum wage increases propensity to collude since benefits of deviation are smaller. This is true when considering subsets of states separately. A substantive increase in the minimum for the federal MW states causes collusion to increase, and makes the period of cooperation relatively longer (at least in the 90s). For the subset of states with own minimum wages, hikes in the minimums in 2000s contributed to greater collusion, while the remaining states exhibite greater degree of deviation from the collusive path.

Howver, on average $3.81 \%$ of otherwise higher wage observations within the lowest quartile are drawn to the minimum in the states with federal MW, versus $3.63 \%$ in the states with own MW regulation, with the latter being more volatile.

certain degree of confidence.

${ }^{6}$ I report the 'cause' measure estimate of collusion by relating collusive minimum wage observations to the lower quartile of wages for ease of presentation. Extending the number of observations to include the upper quartiles will proportionately reduce the fractions without affecting the overall pattern. 
Percentage of Wage Observations at MW(+50c) Within 1st Quartile of Hourly Wages

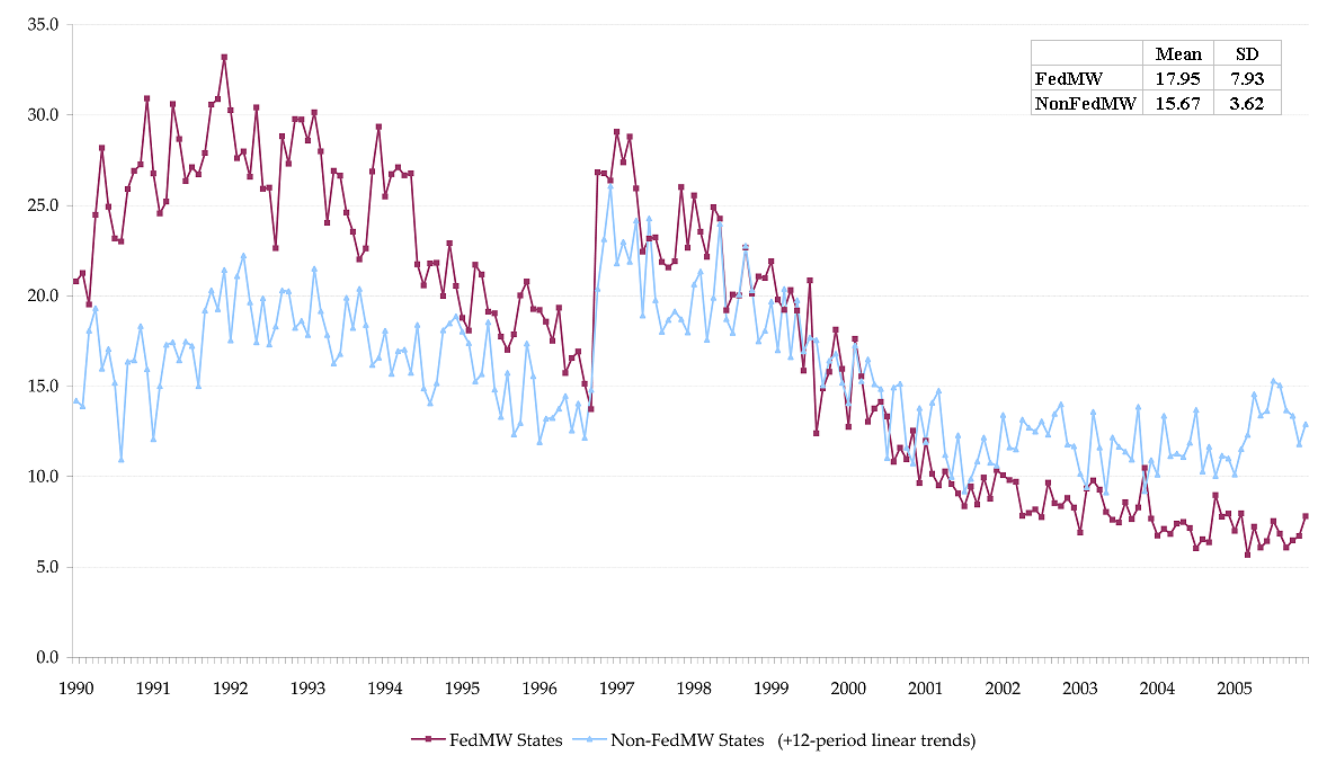

Figure 7: Minimum Wage Observations

Percentage of Potentially Collusive Wages at MW(+50c) Within 1st Quartile of Hourly Wages ( "Cause" Measure )

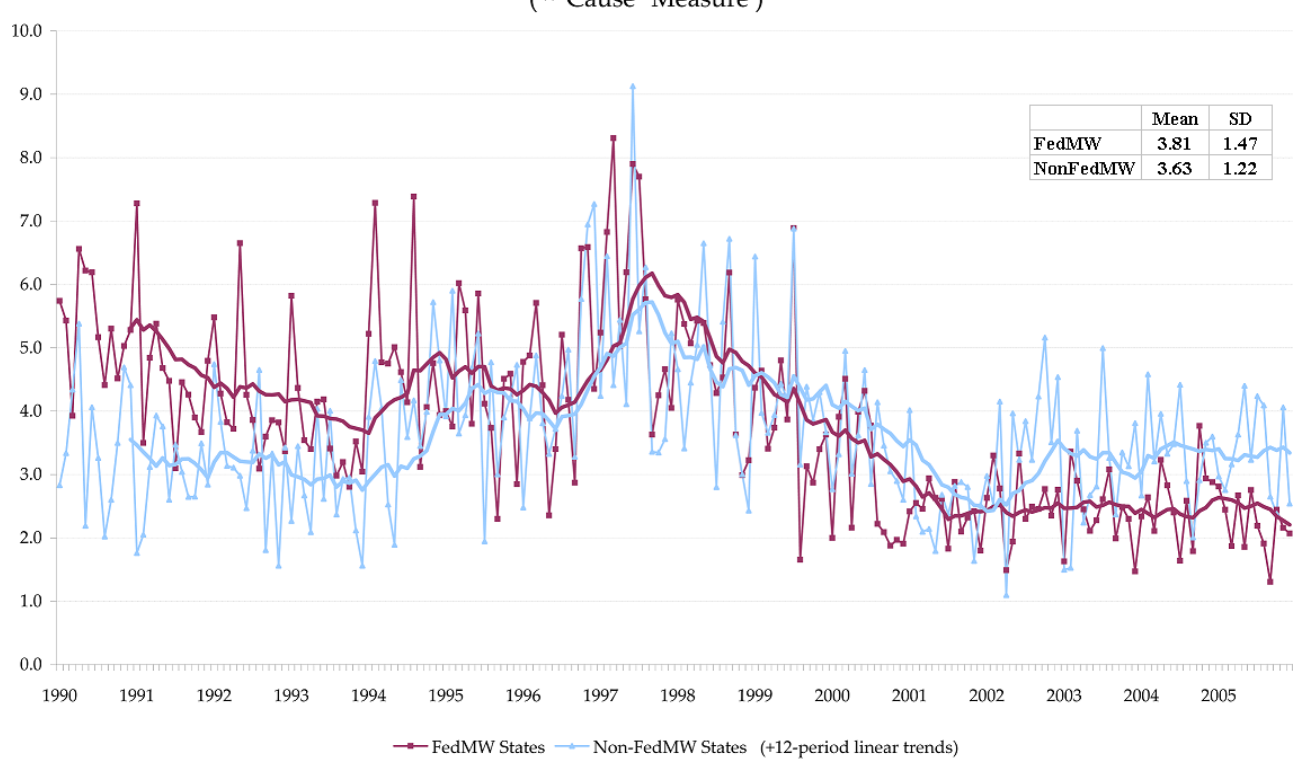

Figure 8: Truncated Regression Results (1) 
Note also that the pattern of change in the size of the MW spike (upper figure) resembles the 'cause' measure of collusion (lower figure) rather closely, though not identically. This suggests there is dependence between the two. Estimating the coefficient of correlation between these two indicators confirms it. The coefficient of correlation between the size of the MW spike and the cause measure of collusion is 0.719 for the subset of states with the federal minimum and 0.478 for the other states. This suggests that the formation of the minimum wage spike could be largely due to collusive dynamics, and more so in the states with a stable focal point - the ones following the federal minimum wage law.

Assessing the 'effect' measure allows to unveil another empirical implication: if collusion at the non-binding minimum wage takes place then a higher minimum wage should increase wages of workers previously affected by collusive wage-setting. Figure 9 and Appendix 3 present the results. The graph demonstrates that the fraction of minimum wage observations that are collusive drops following the hikes in the minimum wage. Following the federal minimum wage increases of 1990-91 the share of potentially collusive wages was declining for about two years. It reached a local peak in the 1996, immediately before another federal minimum wage hike. After the subsequent increase in 1997 this collusion measure declined for another two years, then steadily climbed (for the states with the federal minimum).

As the real minimum wage erodes and more employers defect from the collusive path, workers who still earn the minimum represent a proportionately larger fraction, reflected by increasing effect measure. This estimates reach levels as high as high as $40 \%$ of all minimum wage workers in the states with federal minimum (April 2004). Nevertheless, among those who earn the minimum the average fraction of potentially collusive is larger in the states with the higher minimum: $19.20 \%$ versus $19.05 \%$.

Thus, the cause and the effect measures of collusion obtained by estimating truncated regressions provide evidence consistent with the predictions of collusion theory. The results suggest that workers earning the minimum wage are consistently underpaid when compared to workers with similar characteristics up along the distribution.

P-Tobit regression results provide additional evidence in support of collusion hypothesis. Estimation of p-Tobit required clearcut censoring, which I force. This has lead to the inclusion of below-the-minimum wage observations, which was not used in the case of truncated regressions. Thus, the spike becomes artifically larger, and the results of the two estimation methods cannot be compared directly. In addition, I delete observations for 
Percentage of Potentially Collusive Wages at MW(+50c)

( "Effect" Measure)

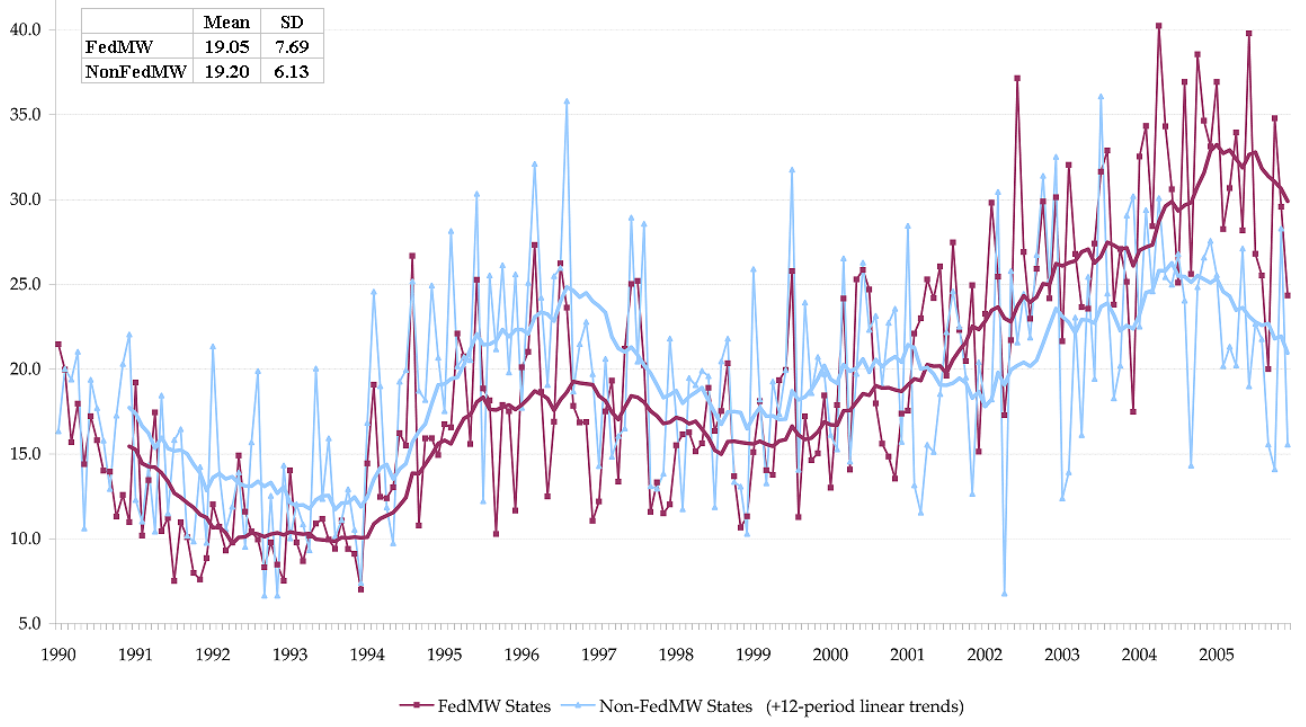

Figure 9: Truncated Regression Results (2)

the food industry adult employees who report hourly wages below the mandated minimum (21 years and older, since this subgroup of workers is most likely to earn tips while working in food establishments that serve alcohol). Deletes represented on average $0.4 \%$ of the sample.

Additionally, when estimating the likelihood of collusion by p-Tobit I pool monthly data into annual sets (factoring out state and month fixed effects). As a result, the obtained probability parameter measures the annual average estimate of potential collusion, similar to the 'cause' measure. Regressions were estimated using the data for the full sample of hourly workers and the subsample of workers employed in states with the federal minimum. All estimates were heteroscedasticity corrected, with robust standard errors. The results are reported in Table 1 and in Figure 10. Note that unlike the reported cause and effect measures calculated based on truncation results, the results on p-Tobit use a different reference scale: the entire wage distribution instead of the lower quartile.

The p-Tobit results show that the pattern of collusion is generally preserved. The estimates of $p$ (roughly equivalent to the 'cause' measure) show 
Table 1: P-Tobit Results

\begin{tabular}{|c|c|c|c|c|c|c|c|c|}
\hline & 1990 & 1991 & 1992 & 1993 & 1994 & 1995 & 1996 & 1997 \\
\hline \multicolumn{9}{|c|}{ All hourly employees } \\
\hline Estimate of $\mathrm{P}^{\dagger}$ & 0.050 & 0.052 & 0.060 & 0.050 & 0.126 & 0.142 & 0.137 & 0.147 \\
\hline Robust SE & 0.010 & 0.010 & 0.010 & 0.009 & 0.015 & 0.015 & 0.024 & 0.028 \\
\hline$\%$ obs at/below MW & 2.44 & 3.10 & 2.71 & 2.34 & 2.95 & 2.47 & 2.51 & 3.49 \\
\hline \multicolumn{9}{|l|}{ Coll. obs/MW obs } \\
\hline ('Effect' measure equivalent) & 2.11 & 1.73 & 2.30 & 2.19 & 4.75 & 5.39 & 6.41 & 4.41 \\
\hline \multicolumn{9}{|c|}{ Hourly employees in states with federal minimum wage } \\
\hline Estimate of $\mathrm{P}$ & 0.039 & 0.047 & 0.056 & 0.046 & 0.102 & 0.130 & 0.151 & 0.121 \\
\hline Robust SE & 0.011 & 0.013 & 0.013 & 0.012 & 0.019 & 0.020 & 0.031 & 0.033 \\
\hline$\%$ obs at/below MW & 2.85 & 3.72 & 3.04 & 2.56 & 3.34 & 2.67 & 2.70 & 3.55 \\
\hline \multicolumn{9}{|l|}{ Coll. obs /MW obs } \\
\hline ('Effect' measure equivalent) & 1.39 & 1.28 & 1.90 & 1.83 & 3.29 & 5.43 & 6.39 & 3.75 \\
\hline N1 & 107425 & 104517 & 103584 & 102177 & 101429 & 101940 & 91461 & 92954 \\
\hline \multirow[t]{2}{*}{$\mathrm{N} 2$} & 59642 & 58673 & 58983 & 58698 & 58164 & 58705 & 52304 & 52970 \\
\hline & 1998 & 1999 & 2000 & 2001 & 2002 & 2003 & 2004 & 2005 \\
\hline \multicolumn{9}{|c|}{ All hourly employees } \\
\hline Estimate of $\mathrm{P}$ & 0.147 & 0.124 & 0.114 & 0.101 & 0.139 & 0.183 & 0.162 & 0.145 \\
\hline Robust SE & 0.017 & 0.015 & 0.014 & 0.013 & 0.014 & 0.017 & 0.016 & 0.016 \\
\hline$\%$ obs at/below MW & 3.32 & 2.54 & 2.01 & 1.85 & 1.78 & 1.97 & 1.86 & 2.23 \\
\hline \multicolumn{9}{|l|}{ Coll. obs/MW obs } \\
\hline ('Effect' measure equivalent) & 4.99 & 5.44 & 6.29 & 5.97 & 8.89 & 11.13 & 10.20 & 7.45 \\
\hline \multicolumn{9}{|c|}{ Hourly employees in states with federal minimum wage } \\
\hline Estimate of $\mathrm{P}$ & 0.161 & 0.112 & 0.106 & 0.090 & 0.127 & 0.184 & 0.127 & 0.120 \\
\hline Robust SE & 0.24 & 0.019 & 0.018 & 0.015 & 0.018 & 0.022 & 0.019 & 0.019 \\
\hline$\%$ obs at/below MW & 3.36 & 2.41 & 1.68 & 1.37 & 1.30 & 1.46 & 1.34 & 1.33 \\
\hline \multicolumn{9}{|l|}{ Coll. obs / MW obs } \\
\hline ('Effect' measure equivalent) & 5.53 & 5.10 & 6.91 & 7.12 & 11.03 & 15.24 & 10.66 & 10.16 \\
\hline$\overline{\mathrm{N} 1}$ & 92978 & 93889 & 94229 & 100060 & 106659 & 105138 & 3103411 & 104684 \\
\hline N2 & 53139 & 53813 & 53805 & 55952 & 59405 & 58711 & 57657 & 57390 \\
\hline
\end{tabular}

\footnotetext{
${ }^{\dagger}$ Estimates multiplied by 100 since $\mathrm{P}$ is small. All significant at $1 \%$ level.
} 

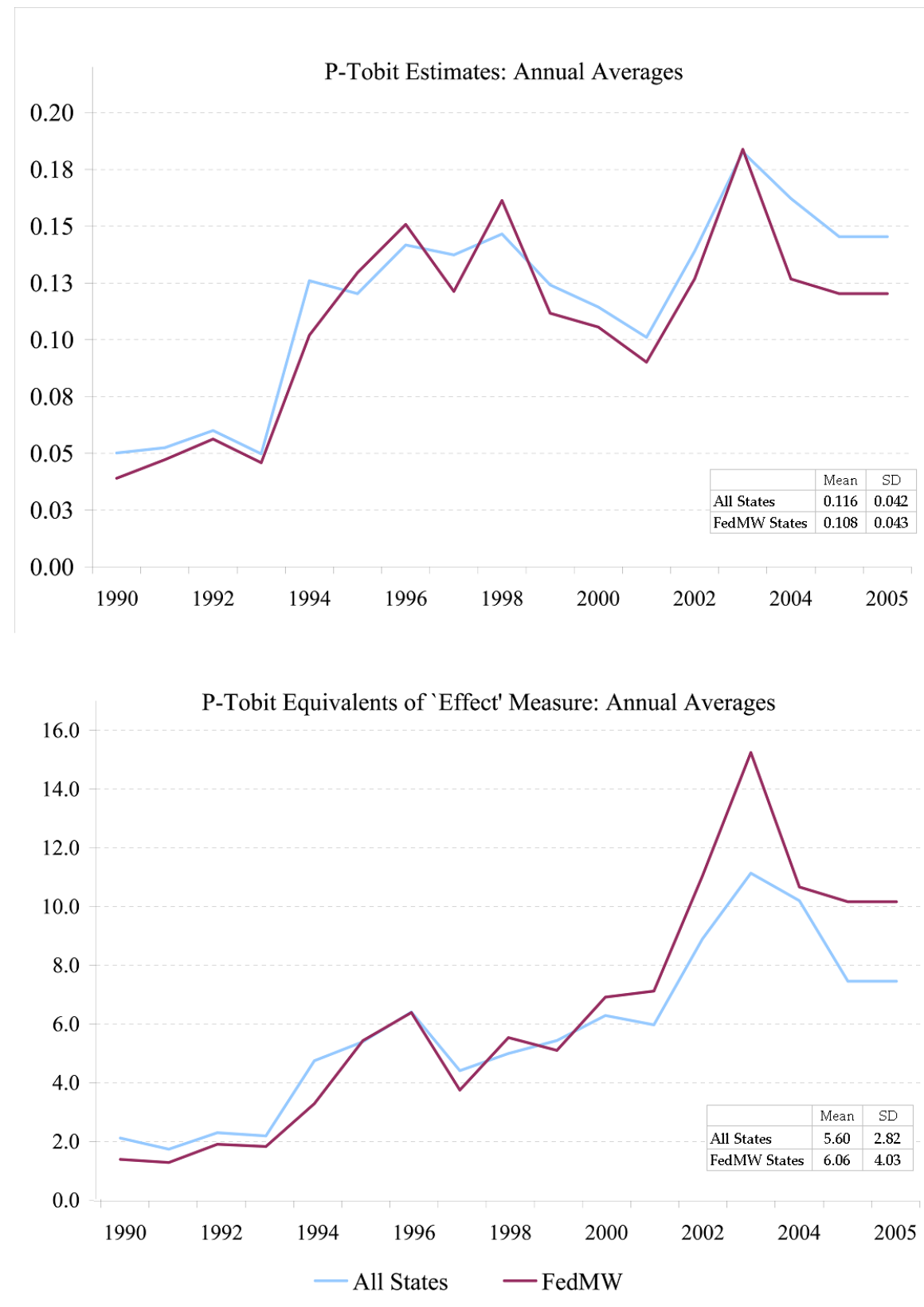

Figure 10: P-Tobit Regression Results 
the collusion intenisfies prior to the minimum wage hikes (clearly so for the 1996-1997 increases). The annual average $p$ for the full sample is estimated at $0.12 \%$ of all hourly workforce (fraction of minimum wage earners whose wages are affected by collusion within the entire pool of non-minimum wages), and actually lower at $0.11 \%$ for the subset of states with the federal minimum. One can also observe that collusion decreases as the minimum wage erodes. This again is consistent with the theoretical predictions.

The graphs also reveal a new spike: the estimates of $p$ increase dramatically following the recession of 2001. This reiterates the conclusion of Rotemberg and Saloner (1996) that collusion is more difficult to sustain during periods of high demand and easier during economic downturns. This additional spike, however, is most likely generated due to relative increase in the number of workers earning wages below the minimum that truncated regression did not account for. Perhaps, this indicates some new dynamics in low-wage sectors, analysis of which is out of scope of this paper.

Overall, the results of both $\mathrm{p}$-Tobit and truncated regressions provide meaningful statistical evidence indicating some trends in wage-setting behavior that is consistent with prediction of collusion theory.

One possible argument may arise pointing that the regressions did not account for some unobservable characteristics common to minimum wage workers that might be driving the results. This possibility cannot be entirely ruled out. However, the fact that the identical estimation procedure was consistently applied to all sets of data allows to assume that the relative impact from omitting possible unobservables would be similar. Thus, a somewhat continuous pattern of collusive shares and its rule-like responses to changes in the minimum wage suggests that low-wage employers act strategically when setting wages.

\section{Probit Model: Test of Facilitating Factors}

The next step in the empirical investigation of the collusion is to test the theory of facilitating factors. I use probit regressions, pooling cross-sections of monthly data into a single data set, with a dependent variable indicating whether a wage observation is collusive based on truncated regression results. The process of selecting the observations is explained in section 4 .

Constrained by the available data, the following variables were included as proxies for the facilitating factors:

- A set of variables indicating time periods since/until changes in the minimum wage level. These variables indicate the effects of "changes- 
in-minimum-wage' factors discussed in the section on empirical implications. Minimum wage hikes are predicted to facilitate collusion either due to the greater overall bindedness, or due to its signalling role indicating the start of a new cooperation game. It is reasonable to expect that the relationship between the time elapsed since/until the latest minimum wage hike and the probability of collusion is nonlinear. Thus, I create a set of binary variables by grouping observations according to the time period relative to the next minimum wage change: the actual month of minimum wage change, 2 to 6 months since/until the change, 7 to 12 months since/until the change, and more than 12 months since/until the change.

- A variable 'wages of college graduates' is chosen as a proxy for 'costs of other inputs', another facilitating factor. The variable was constructed using the information available in the CPS. I divided the respondents into age groups unique for each state and month. Respondents aged from 15 to 65 years old were split into 10 five-year age intervals. Average ages for college graduates were then calculated wages for each age group. The wages of both hourly and non-hourly workers with college degrees were used. A positive coefficient on this variable is expected since higher input costs increase the attractiveness of collusion.

- The monthly prime interest rate is chosen as an alternative proxy for costs of other inputs, in this case the cost of capital. Positive coefficient is expected.

- Monthly state unemployment rates were included as a proxy for demand conditions with a purpose of testing another empirical implication: in periods of high demand collusion is less likely. I chose to include unemployment rates that are not seasonally adjusted, as able to fully reflect variation in local labor market conditions. A positive coefficient is expected, since poor market conditions increase incentives to cooperate.

- Two proxies for the number of firms in the labor market were entered: a 'central city' dummy and a 'metropolitan area, not central city' dummy (compared against rural areas). These variables were chosen as proxies for the number of firms in the market. All things equal, rural areas should exhibit greater cooperation, as number of employers in the market is the smallest. Thus, the negative coefficients for the 
included variables are expected, with marginally smaller coefficient for metropolitan area (not central city) ${ }^{7}$.

- A dummy for the state that follows the federal minimum wage regulation was also entered as a proxy for stability of the focal point.

In addition to the listed above, I include the minimum wage and the real minimum wage variables. As was already discussed, a higher minimum wage as it leads to greater collusion also brings wages of previously affected closer to the competitive level.

The results of probit regressions are reported in Table 2. Five different specifications were estimated.

The signs of the slope coefficients are generally consistent with theoretical predictions. The estimates on the set of dummy variables indicating the responsiveness of propensity to collude to changes in the minimum wage change confirm that collusion is reinforced when minimum wage is raised, or the raise is unticipated. The coefficient on the "month of minimum wage change' variable is positive and significant, and its contribution to the overall probability is the largest among time variables.

The next time variable having the largest marginal effect on propensity to collude is the dummy indicating the coming minimum wage hike -2 to 6 month until. The coefficients are positive and significant as expected, indicating that employers respond positively to the upcoming change, as it is equivalent to the cost increase, or can be alternatively viewed as a signal to starting a new game. Note that the meaning of this coefficient is that employers are more likely to collude at the 'old', not the new minimum wage, if the shift in the minimum is unticipated.

As a new minimum wage law take effect, employers are more likely drawn to the focal collusive path, however this effect diminishes the longer the time period since the change. This is reflected in the positive but small (in specification 3) or insignificant coefficients on variable ' 7 to 12 month since the hike'. Note that all coefficients are relative to the excluded category ' 13 and more months'.

Wages of college graduates used as a proxy for costs of other inputs also confirm the predictions of the theory of facilitating factors. The estimated coefficients are positive, supporting the prediction that higher costs lead to greater collusion. The coefficients are significant for all model specifications and their values are robust to changes in specifications.

\footnotetext{
${ }^{7}$ I thank Dan Hammermesh for his suggestion to make such comparison in order to identify collusion.
} 


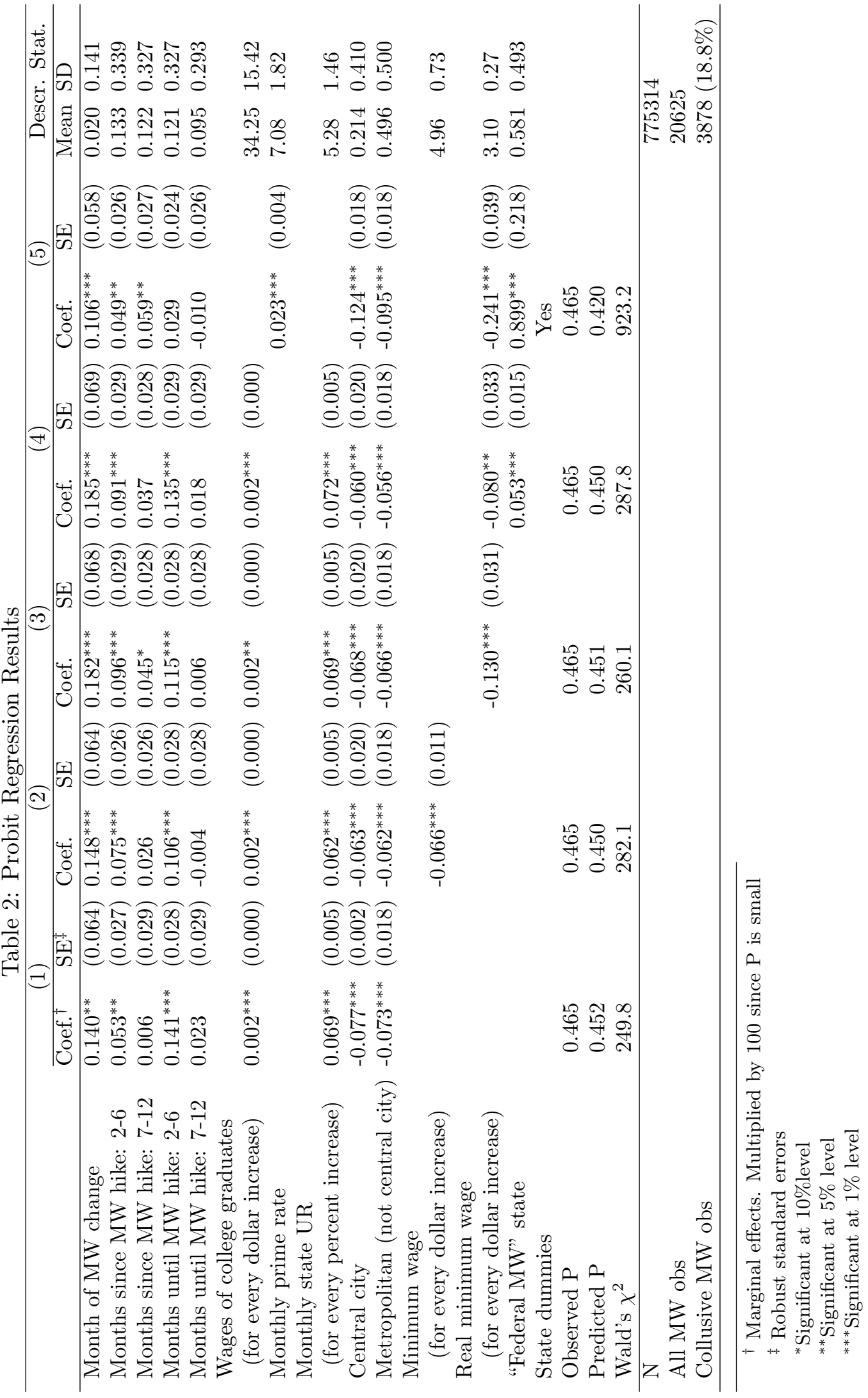


In the specification 5 I use another proxy for the input costs - the monthly prime interest rate as the cost of borrowing. The estimated coefficient is positive and significant, also consistent with theoretical predictions on the costs of inputs.

State and month specific unemployment rates were used as a proxy for demand conditions. Coefficients in all specifications are positive and significant, supporting the theory that in poor demand conditions collusion is more likely. Since I use unemployment rates that are not seasonally adjusted, I do not include seasonal fixed effects. Also, the unemployment rates vary greatly by state, which absorbs to large extent the states' heterogeneity.

Two binary variables chosen as proxies for the number of firms in the market are the 'central city' and 'metropolitan/not central city' variables, compared against rural area observations. As anticipated, collusion is the greatest in rural areas where employer coordination is the easiest, it is smaller in towns, and the smallest in large cities where coordination is the most difficult. The coefficients have expected signs and significant in all specifications.

Minimum wage and real minimum wage variables are introduced in specifications $2-5$ show that a relatively more binding minimum wage reduces the number of workers affected by collusive wage-setting: the estimated coefficients are negative and significant. It reiterates the hypothesis that the recent minimum wage hikes were not binding, were able to increase wages and reduced the extent of collusion.

The last variable in the probit equations is the dummy denoting worker's employment in a state with the federal minimum. Viewing this variable as a proxy for the stability of the focal point and the associated possibility for learning to cooperate can explain the positive (and significant) coefficient. It also informs that workers in theses states during the covered period were more likely affected. The coefficient also points out that the estimation of the 'cause' collusion measure by ML truncated regressions is, perhaps, more appropriate than p-Tobit.

In summary, the results of the probit models provide strong statistical and theoretically meaningful evidence in support of the collusion hypothesis. 


\section{Conclusion}

This paper was an attempt to explain some interesting empirical phenomena found in low-wage labor markets. Perhaps, the most visible among them is the minimum wage spike puzzle. By combining industrial organization theories of tacit collusion and focal points with labor market analysis, this paper broadens the range of possible explanations of the spike and points out a new role that the minimum wage plays in the low-wage markets. Namely, I suggest that in the infinite game of wage-setting employers are likely to tacitly collude if offered a focal point - the non-binding minimum wage. The outcome, a stable but socially inefficient collusive equilibrium, results on monopsony-like labor markets.

The collusion hypothesis is tested empirically by analyzing the empirical implications of tacit collusion in the form of lowered wages, their clustering, and their responsiveness to the facilitating factors. The results provide strong indication that the tacit collusion affects the low-wage markets. Both truncated and p-Tobit regressions show that the fraction of low-wage workers affected by collusive wage-setting rises when the minimum wage is raised, however the results also indicate that some workers benefit since their previously collusive wages are now closer to the competitive levels.

Regressions also demonstrate that propensity to collude is consistent with predictions of the IO theory of facilitating factors. All three models point towards existence of strategic behavior by employers, with workers in the subset of states that follow the federal minimum wage regulation being more affected during the investigated period.

Thus, the paper unravels the sequence of questions posed in the introduction. If current level of minimum wage is non-binding for employers who happen to tacitly collude, an increase to another non-binding level will increase overall wages and will have no effect on employment. Successful collusion makes employers earn extra-marginal profits, contributing to higher than average rate of job creation in the low-wage sectors, frequently observed in the data. By assuming collusion, one can also understand why low-wage employers are unwilling to raise wages even when unable to hire workers because of the threat of retaliation. And importantly, collusion can play an important role in explaining slow growth in earnings of the low-wage workers and resulting rise in the wage inequality.

As the results indicate, a higher minimum wage has both negative and the positive effect on collusion, and these marginal effects should be taken into account when minimum wage policies are formulated. It should not be assumed that by simply raising the minimum wage the problem of collusion 
at the minimum will be eliminated. For a policy-maker, raising the minimum wage poses two questions. First, at what value it should be set, which calls for the search of a just-binding level. The choice of such a level could, however, be a double-edged sword: a uniform minimum wage will likely be binding for some industries, resulting in layoffs, and non-binding for others, contributing to collusion. And, as the paper suggests, the nonbinding minimum could become the focal minimum. From this perspective, one can argue that an industry-specific or a locality-specific minimum wage should be preferred to the uniform minimum wage.

The second question that a policy-maker addresses is how often an existing minimum wage should be raised. If collusion at the non-binding minimum wage is real, it calls for more frequent changes in its levels. However, if these changes are anticipated, it would not alleviate the collusion problem. Moreover, if the coming hikes in the minimum wage (and their magnitudes) is known in advance, it is equivalent to having a stable focal point, and the wage-lifting effect will be minimal.

As tacit collusion by wage-setting employers at the non-binding minimum wage is a very likely state that the low-wage markets are in, the reader should be cautioned that the evidence I present in the paper is indirect (though tacit collusion is hard to prove in general). There can be pointed out at least two ways that could improve upon the results and get more immediate evidence of collusion. First, obtaining a joint employer-employee dataset that included a set of variables describing firms' size, sales, costs, profits, hiring and firing activity would allow to establish a more direct link between firm's performance and collusion. No publicly available dataset in the US (and to my knowledge no administrative set either) has such combination of variables. Second, having a control group of markets that is not affected by the minimum wage regulations would also allow for better identification of the relationship. As was previously discussed, such control groups are rather difficult to locate when using the US data. A possible solution lies in investigating the possibilities of using foreign data.

Overall, the research suggests the role that a non-binding minimum wage plays as a possible focal point for tacit collusion by employers should be taken into account by policy-makers who design labor market policies aimed at improving earnings of the low paid. The redistributive efficacy of the minimum wage is jeopardized if it becomes the reference point for collusion, and should be further analyzed. 


\section{References}

Alpert, W. (1986). The Minimum Wage in the Restaurant Industry. Praeger.

Baldwin, L., Marshall, R., \& Richard, J. (1997). Bidder Collusion at Forest Service Timber Sales. Journal of Political Economy, 105(4), 657-99.

Binmore, K., \& Samuelson, L. (2006). The Evolution of Focal Points. Games and Economic Behavior, 56(1), 21-42.

Borenstein, S., \& Shepard, A. (1996). Dynamic Pricing in Retail Gasoline Markets. RAND Journal of Economics, 27(3), 429-51.

Brown, C. (1999). Minimum Wages, Employment and the Distribution of Income.. In Handbook of Labor Economics. Vol.3B., chap. 32. Elsevier.

Burdett, K., \& Mortensen, D. (1998). Wage Differentials, Employer Size and Unemployment. International Economic Review, 39(2), 257-273.

Burkhauser, R., Couch, K., \& Glenn, A. (1996a). Public Policies for the Working Poor: The Earned Income Tax Credit versus Minimum Wage Legislation, Vol. 15, chap. Research in Labor Economics, pp. 65-109.

Burkhauser, R., Couch, K., \& Wittenburg, D. (1996b). Who Gets What from Minimum Wage Hikes: A Re-Estimation of Card and Krueger's Distributional Analysis in "Myth and Measurement: The New Economics of the Minimum Wage". Industrial and Labor Relations Review, $49(3), 547-552$.

Burkhauser, R., Couch, K., \& Wittenburg, D. (2000). A Reassessment of the New Economics of the Minimum Wage Literature with Monthly Data from Current Population Survey. Journal of Labor Economics, 18(4), 653-680.

Card, D., \& Krueger, A. (1995). Myth and Measurement: the New Economics of the Minimum Wage. Princeton University Press.

Christie, William, J. H., \& Schultz, P. (1994). Why did Nasdaq market makers stop avoiding odd-eighth quotes?. Journal of Finance, pp. 1841-1860.

Colman, A. (1997). Salience and Focusing in Pure Coordination Games. Journal of Economic Methodology, 4(1), 61-81. 
Crawford, V., \& Haller, H. (1990). Learning How to Cooperate: Optimal Play in Repeated Coordination Games. Econometrica, 58(3), 571-95.

Currie, J., \& Fallick, B. (1996). The Minimum Wage and the Employment of Youth: Evidence from the NLSY. Journal of Human Resources, 31, 404-428.

Dickens, R., Machin, S., \& Manning, A. (1998). Estimating the Effect of Minimum Wages on Employment from the Distribution of Wages: A Critical View. Labour Economics, 5, 109-134.

Dickens, R., \& Manning, A. (2004). Has the National Minimum Wage Reduced UK Wage Inequality?. Journal of the Royal Statistical Society: Series A, 167, 613-626.

DiNardo, J., Fortin, N., \& Lemieux, T. (1996). Labor Market Institutions and the Distribution of Wages, 1973-1992: A Semiparametric Approach. Econometrica, 64 (5), 1001-1044.

Flinn, C. (2003). Minimum Wage Effects on Labor Market Outcomes under Search with Bargaining. Discussion paper 949, IZA.

Forsythe, J. (1939). Legislative History of the Fair Labor Standards Act. Law and Contemporary Problems, 6(3), 464-490.

Freeman, R. (1996). The Minimum Wage as a Redistributive Tool. The Economic Journal, 106, 639-649.

Gottschalk, P. (1997). Inequality, Income Growth, and Mobility: The Basic Facts. Journal of Economic Perspectives, 11(2), 21-40.

Harvey, D. (2006). Anticompetitive Social Norms as Antitrust Violations. California Law Review, 94(769).

Howell, D., Duncan, M., \& Harrison, B. (1998). Low Wages in the US and High Unemployment in Europe: A Critical Assessment of the Conventional Wisdom. CEPA Working Paper Series.

Janssen, M. (2001). Rationalizing Focal Points. Theory and Decision, 50(2), 119-148.

Knittel, C., \& Stango, V. (2003). Price Ceilings as Focal Points for Tacit Collusion: Evidence from Credit Cards. The American Economic Review, 93(5), 1703-1829. 
Lee, D. (1999). Wage Inequality in the United States during the 1980s: Rising Dispersion or Falling Minimum Wage. Quarterly Journal of Economics, 114(3), 977-1023.

Machin, S., Manning, A., \& Lupin, R. (2003). Where the Minimum Wage Bites Hard: Introduction of Minimum Wages to a Low Wage Sector. Journal of the European Economic Association, 1(1), 154-180.

Manning, A. (2003a). Monopsony in Motion. Princeton University Press.

Manning, A. (2003b). The Real Thin Theory: Monopsony in Modern Labour Markets. Labour Economics, 10(2), 105-131.

Meyer, R., \& Wise, D. (1983). Discontinuous Distributions and Missing Persons: the Minimum Wage and Unemployed Youth. Econometrica, 51, 1677-1698.

Moertti, E., \& Perloff, J. (2000). Minimum Wage Laws Lower Some Agricultural Wages. Working paper series, Institute for Research on Labor and Employment, UCLA Berkley.

Neumark, D., Schweitzer, M., \& Wascher, W. (2004). Minimum Wage Effects Throughout the Wage Distribution. Journal of Human Resources, $39(2), 425-50$.

Neumark, D., \& Wascher, W. (1996). Employment Effects of Minimum and Subminimum Wages: Reply to Card, Katz and Krueger. Industrial and Labor Relations Review, 47(3), 497-512.

Neumark, D., \& Wascher, W. (2000). Minimum Wage and Employment: A Case-Study of the Fast-Food Industry in New-Jersey and Pennsylvania: Comment. The American Economic Review, 90(5), 1362-1396.

Porter, R. (2005). Detecting Collusion. Review of Industrial Organization, 26, 147-167.

Richards, T., Paterson, P., \& Acharya, R. (2001). Price Behavior in a Dynamic Oligopsony: Washington Processing Potatoes. American Journal of Agricultural Economics, 83(2), 259-71.

Rotemberg, J., \& Saloner, G. (1986). A Supergame-Theoretic Model of Price Wars During Booms. American Economic Review, 76(3), 390-407.

Schelling, T. (1960). The Strategy of Conflict. Hravard Univesrity Press, Cambridge, Mass. 
Schelling, T. (1973). Hockey Helmets, Concealed Weapons, and Daylight Saving: A Study of Binary Choices with Externalities. The Journal of Conflict Resolution, 17(3), 381-428.

Stewart, M. (2004). The Impact of the Introduction of the U.K. Minimum Wage on the Employment Probabilities of Low-Wage Workers. Journal of the European Economic Association, 2(1), 67-97.

Teulings, C. (2003). The Contribution of Minimum Wages to Increasing Wage Inequality. The Economic Journal, 113(490), 801-833.

Tirole, J. (1988). The Theory of Industrial Organization. MIT Press, Cambridge, Mass.

Wessels, W., Zapf, H., Brubeck, M., \& Theune, C. (1980). Minimum Wages, Fringe Benefits and Working Conditions. American Enterprise Institute. 
Appendix 1

Minimum Wage: State and Federal Increases (1990-2005)

\begin{tabular}{|c|c|c|c|c|c|c|c|c|c|c|c|c|c|c|c|c|c|}
\hline & & 1990 & 1991 & 1992 & 1993 & 1994 & 1995 & 1996 & 1997 & 1998 & 1999 & 2000 & 2001 & 2002 & 2003 & 2004 & 2005 \\
\hline $\mathrm{AK}$ & & Apr & Apr & & & & & & Sep & & & & & & Jan & & \\
\hline An & 3.35 & 4.30 & 4.75 & & & & & & 5.65 & & & & & & 7.15 & & \\
\hline CA & & & & & & & & & Mar & Mar & & & Jan & Jan & & & \\
\hline - & 4.25 & & & & & & & & 5.00 & 5.75 & & & 6.25 & 6.75 & & & \\
\hline$C T$ & & & Apr & & & & & Oct & & Sep & Jan & Jan & Jan & Jan & Jan & Jan & \\
\hline$c_{1}$ & 4.25 & & 4.27 & & & & & 4.27 & & 5.18 & 5.65 & 6.15 & 6.40 & 6.70 & 6.90 & 7.10 & \\
\hline $\mathrm{DE}$ & 3.35 & & & & & & & & $\begin{array}{l}\text { Mar } \\
5.00\end{array}$ & & $\begin{array}{c}\text { May } \\
5.65\end{array}$ & $\begin{array}{l}\text { Oct } \\
6.15\end{array}$ & & & & & \\
\hline DC & & & & & Oct & & & & & & Jan & & & & & & Jan \\
\hline & 4.75 & & & & 5.45 & & & & & & 6.15 & & & & & & 6.60 \\
\hline FL & 3.35 & & & & & & & & & & & & & & & & $\begin{array}{r}\text { May } \\
6.15\end{array}$ \\
\hline $\mathrm{HI}$ & 3.85 & & & & $\begin{array}{l}\text { Jan } \\
5.25\end{array}$ & & & & & & & & & $\begin{array}{l}\text { Jan } \\
5.75\end{array}$ & $\begin{array}{l}\text { Jan } \\
6.25\end{array}$ & & \\
\hline IA & 3.35 & & $\begin{array}{l}\text { Jan } \\
4.25\end{array}$ & $\begin{array}{l}\text { Jan } \\
4.65\end{array}$ & & & & & & & & & & $\begin{array}{l}\text { Jan } \\
5.75\end{array}$ & & & \\
\hline IL & 3.35 & & & & & & & & & & & & & & & $\begin{array}{l}\text { Jan } \\
5.50\end{array}$ & $\begin{array}{l}\text { Jan } \\
6.50\end{array}$ \\
\hline MA & 3.75 & & & & & & & $\begin{array}{l}\text { Jan } \\
4.75\end{array}$ & $\begin{array}{l}\text { Jan } \\
5.25\end{array}$ & & & $\begin{array}{l}\text { Jan } \\
6.00\end{array}$ & $\begin{array}{l}\text { Jan } \\
6.75\end{array}$ & & & & $\begin{array}{l}\text { Oct } \\
6.50\end{array}$ \\
\hline $\mathrm{ME}$ & 3.75 & $\begin{array}{l}\text { Jan } \\
3.85\end{array}$ & $\begin{array}{l}\text { Jan } \\
3.95\end{array}$ & & & & & & & & & & & & $\begin{array}{l}\text { Jan } \\
6.25\end{array}$ & $\begin{array}{l}\text { Oct } \\
6.35\end{array}$ & \\
\hline $\mathrm{MN}$ & 3.85 & $\begin{array}{l}\text { Jan } \\
3.95\end{array}$ & & & & & & & & & & & & & & & $\begin{array}{r}\text { Aug } \\
6.15\end{array}$ \\
\hline $\mathrm{NJ}$ & 3.35 & & & $\begin{array}{l}\text { Apr } \\
5.05\end{array}$ & & & & & & & & & & & & & $\begin{array}{l}\text { Oct } \\
6.15\end{array}$ \\
\hline $\mathrm{NH}$ & 3.65 & $\begin{array}{l}\text { Jan } \\
3.75\end{array}$ & $\begin{array}{l}\text { Jan } \\
3.85\end{array}$ & $\begin{array}{l}\text { Jan } \\
3.95\end{array}$ & & & & & & & & & & & & & \\
\hline NY & 3.35 & & & & & & & & & & & & & & & & $\begin{array}{l}\text { Jan } \\
6.00\end{array}$ \\
\hline OR & & Jan & Jan & & & & & & Jan & Jan & Jan & & & & Jan & Jan & Jan \\
\hline RI & $\begin{array}{l}3.85 \\
4.25\end{array}$ & 4.25 & 4.75 & & & & & & 5.50 & 6.00 & $\begin{array}{c}6.50 \\
\text { Jul } \\
5.65\end{array}$ & $\begin{array}{l}\text { Sep } \\
6.15\end{array}$ & & & 6.90 & $\begin{array}{l}7.05 \\
\text { Jan } \\
6.75\end{array}$ & 7.25 \\
\hline VT & 3.75 & $\begin{array}{c}\text { Jul } \\
3.85\end{array}$ & & & & & $\begin{array}{l}\text { Feb } \\
4.50\end{array}$ & $\begin{array}{l}\text { Feb } \\
4.75\end{array}$ & $\begin{array}{l}\text { Jan } \\
5.00\end{array}$ & & $\begin{array}{l}\text { Oct } \\
5.75\end{array}$ & & $\begin{array}{l}\text { Jan } \\
6.25\end{array}$ & & & $\begin{array}{l}\text { Jan } \\
6.75\end{array}$ & $\begin{array}{l}\text { Jan } \\
7.00\end{array}$ \\
\hline WA & 3.85 & $\begin{array}{l}\text { Jan } \\
4.25\end{array}$ & & & & & $\begin{array}{l}\text { Jan } \\
4.90\end{array}$ & & & & $\begin{array}{l}\text { Jan } \\
5.70\end{array}$ & $\begin{array}{l}\text { Jan } \\
6.50\end{array}$ & $\begin{array}{l}\text { Jan } \\
6.72\end{array}$ & $\begin{array}{l}\text { Jan } \\
6.90\end{array}$ & $\begin{array}{l}\text { Jan } \\
7.01\end{array}$ & $\begin{array}{l}\text { Jan } \\
7.16\end{array}$ & $\begin{array}{l}\text { Jan } \\
7.35\end{array}$ \\
\hline WI & 3.35 & & & $\begin{array}{l}\text { Mar } \\
4.25 \\
\end{array}$ & & & & & & & & & & & & & $\begin{array}{l}\text { Jun } \\
5.70\end{array}$ \\
\hline US & & Apr & Apr & & & & & Oct & Sep & & & & & & & & \\
\hline & 3.35 & 3.80 & 4.25 & & & & & 4.75 & 5.15 & & & & & & & & \\
\hline
\end{tabular}

Sources:

US Department of Labor

Monthly Labor Review: 1989-2006

Fiscal Policy Institute: http://www.fiscalpolicy.org, 2006 
List of Regressors, Wage Equation

\begin{tabular}{|c|c|}
\hline Demographic variables & $\begin{array}{l}\text { Age } \\
\text { Age squared } \\
\text { Male } \\
\text { Married, spouse present } \\
\text { Black } \\
\text { Hispanic } \\
\text { Foreign born } \\
\text { Not a citizen }\end{array}$ \\
\hline Educational groups & $\begin{array}{l}\text { Less than } 8^{\text {th }} \text { grade } \\
\text { High school grades completed, no diploma } \\
\text { High school graduate }{ }^{1} \\
\text { Some college } \\
\text { Associate's degree } \\
\text { Bachelors degree } \\
\text { Master's degree } \\
\text { Professional degree } \\
\text { Doctorate degree }\end{array}$ \\
\hline Time allocation variables & $\begin{array}{l}\text { Part-time labor force } \\
\text { Enrolled in school }\end{array}$ \\
\hline Cost-of-living and local labor market conditions & $\begin{array}{l}\text { Metropolitan area } \\
\text { State dummies }\end{array}$ \\
\hline Industry dummies & $\begin{array}{l}\text { Agriculture, forestry, fishing and hunting } \\
\text { Mining } \\
\text { Construction } \\
\text { Manufacturing } \\
\text { Transportation } \\
\text { Communications } \\
\text { Utilities and sanitary services } \\
\text { Wholesale trade } \\
\text { Retail } \\
\text { Finance, insurance and real estate } \\
\text { Private households } \\
\text { Business, repair, auto personal services } \\
\text { Entertainment and recreation services } \\
\text { Hospitals and other medical services } \\
\text { Educational, social other professional services } \\
\text { Forestry and fisheries } \\
\text { Public administration } \\
\text { (Armed forces excluded) }\end{array}$ \\
\hline Occupation group dummies & $\begin{array}{l}\text { Executive, administrative and managerial } \\
\text { Professional specialty } \\
\text { Technicians and related support } \\
\text { Sales } \\
\text { Administrative support, inc. clerical } \\
\text { Private household } \\
\text { Protective service } \\
\text { Service occ., except protective and household } \\
\text { Precisionn production, craft and repair } \\
\text { Machine operators, assemblers and inspectors } \\
\text { Transportation and material moving } \\
\text { Handlers, equip. cleaners, helpers, laborers } \\
\text { Farming, forestry and fishing occ. } \\
\text { (Armed forces excluded) }\end{array}$ \\
\hline Other work related variables & Union member / covered by union contract \\
\hline
\end{tabular}


Percentage of Potentially Collusive Observations at MW(+50c), "Effect" Measure

Subset of States Federeal MW

\begin{tabular}{|c|c|c|c|c|c|c|c|c|c|c|c|c|c|c|c|c|c|}
\hline & 1990 & 1991 & 1992 & 1993 & 1994 & 1995 & 1996 & 1997 & 1998 & 1999 & 2000 & 2001 & 2002 & 2003 & 2004 & 2005 & Avg. \\
\hline jan & 21.5 & 19.2 & 12.0 & 14.0 & 14.4 & 16.8 & 20.1 & 12.2 & 15.5 & 15.1 & 13.0 & 17.6 & 23.3 & 21.6 & 32.5 & 36.9 & 19.1 \\
\hline feb & 20.0 & 10.2 & 10.7 & 9.8 & 19.1 & 16.6 & 21.0 & 17.5 & 16.2 & 18.1 & 17.9 & 22.1 & 29.8 & 32.0 & 34.3 & 28.3 & 20.2 \\
\hline mar & 15.7 & 13.5 & 9.3 & 8.7 & 12.5 & 22.1 & 27.3 & 19.3 & 16.3 & 14.0 & 24.2 & 23.0 & 25.5 & 26.8 & 28.4 & 30.7 & 19.8 \\
\hline apr & 18.0 & 17.4 & 9.8 & 10.2 & 12.4 & 20.8 & 18.7 & 13.4 & 15.2 & 13.8 & 14.1 & 25.3 & 17.3 & 23.6 & 40.2 & 33.9 & 19.0 \\
\hline may & 14.4 & 10.5 & 14.9 & 10.9 & 13.0 & 15.6 & 12.5 & 21.2 & 15.6 & 19.4 & 25.3 & 24.2 & 21.7 & 23.6 & 34.3 & 28.2 & 19.1 \\
\hline jun & 17.2 & 11.2 & 11.6 & 11.2 & 16.2 & 25.3 & 16.9 & 25.0 & 18.9 & 20.0 & 25.8 & 26.1 & 37.2 & 27.4 & 30.6 & 39.8 & 22.5 \\
\hline jul & 15.8 & 7.5 & 10.4 & 10.0 & 15.5 & 18.9 & 26.2 & 25.2 & 16.4 & 25.8 & 24.7 & 19.6 & 26.9 & 31.6 & 25.1 & 26.8 & 20.4 \\
\hline aug & 14.0 & 11.0 & 10.0 & 9.4 & 26.7 & 18.2 & 23.6 & 20.2 & 17.5 & 11.3 & 18.0 & 27.5 & 23.0 & 32.9 & 36.9 & 25.5 & 20.3 \\
\hline sep & 14.0 & 10.1 & 8.3 & 11.1 & 10.8 & 10.3 & 17.8 & 11.6 & 20.3 & 17.2 & 15.6 & 22.3 & 25.9 & 23.8 & 25.6 & 20.0 & 16.5 \\
\hline oct & 11.3 & 8.0 & 9.8 & 9.4 & 15.9 & 17.9 & 16.9 & 13.3 & 13.7 & 14.6 & 14.9 & 20.5 & 29.9 & 27.1 & 38.6 & 34.8 & 18.5 \\
\hline nov & 12.6 & 7.6 & 8.5 & 9.1 & 15.9 & 17.5 & 16.9 & 11.5 & 10.7 & 15.0 & 13.5 & 24.9 & 24.2 & 25.1 & 34.6 & 29.6 & 17.3 \\
\hline dec & 11.0 & 8.9 & 7.5 & 7.0 & 14.9 & 11.7 & 11.1 & 12.0 & 11.3 & 18.4 & 17.4 & 15.1 & 30.1 & 17.5 & 33.1 & 24.3 & 15.7 \\
\hline Avg. & 15.4 & 11.3 & 10.2 & 10.1 & 15.6 & 17.6 & 19.1 & 16.9 & 15.6 & 16.9 & 18.7 & 22.3 & 26.2 & 26.1 & 32.9 & 29.9 & 19.1 \\
\hline \multicolumn{18}{|c|}{ Subset of States with Own MW } \\
\hline & 1990 & 1991 & 1992 & 1993 & 1994 & 1995 & 1996 & 1997 & 1998 & 1999 & 2000 & 2001 & 2002 & 2003 & 2004 & 2005 & Avg. \\
\hline jan & 16.3 & 12.3 & 21.3 & 10.0 & 16.8 & 17.5 & 17.7 & 14.3 & 17.2 & 25.9 & 16.1 & 28.4 & 17.9 & 12.4 & 22.5 & 25.5 & 18.3 \\
\hline feb & 20.0 & 11.0 & 13.9 & 12.0 & 24.6 & 28.1 & 25.1 & 20.6 & 11.7 & 18.2 & 15.3 & 13.2 & 18.2 & 13.9 & 29.4 & 20.2 & 18.5 \\
\hline mar & 19.4 & 14.3 & 10.6 & 10.9 & 19.0 & 20.2 & 32.1 & 14.8 & 19.5 & 13.3 & 26.5 & 11.5 & 30.4 & 23.0 & 24.6 & 21.3 & 19.5 \\
\hline apr & 21.0 & 10.4 & 11.9 & 9.3 & 11.9 & 20.7 & 24.2 & 16.1 & 19.1 & 19.3 & 14.6 & 15.5 & 6.8 & 16.1 & 30.1 & 20.2 & 16.7 \\
\hline may & 10.6 & 18.4 & 13.9 & 20.0 & 9.7 & 20.5 & 19.1 & 16.5 & 19.9 & 17.3 & 19.7 & 15.1 & 25.8 & 25.4 & 25.4 & 27.1 & 19.0 \\
\hline jun & 19.4 & 11.5 & 9.5 & 12.4 & 19.3 & 30.3 & 25.5 & 28.9 & 19.6 & 19.9 & 26.3 & 18.5 & 21.6 & 19.4 & 25.0 & 19.0 & 20.4 \\
\hline jul & 17.7 & 15.8 & 15.7 & 15.9 & 19.9 & 12.2 & 26.0 & 20.4 & 11.9 & 31.7 & 22.3 & 22.2 & 24.4 & 36.1 & 26.8 & 22.7 & 21.4 \\
\hline aug & 15.8 & 16.5 & 19.9 & 10.1 & 25.2 & 25.5 & 35.8 & 28.6 & 20.5 & 14.1 & 23.1 & 24.6 & 21.9 & 24.5 & 24.0 & 21.8 & 22.0 \\
\hline sep & 12.9 & 10.2 & 6.7 & 11.1 & 18.7 & 21.2 & 18.7 & 13.1 & 21.8 & 23.9 & 19.0 & 22.5 & 26.7 & 18.3 & 14.3 & 15.6 & 17.2 \\
\hline oct & 17.3 & 9.8 & 12.5 & 12.9 & 18.2 & 26.1 & 21.5 & 13.0 & 13.3 & 18.6 & 22.7 & 19.5 & 31.4 & 20.2 & 24.8 & 14.1 & 18.5 \\
\hline nov & 20.3 & 14.2 & 6.7 & 10.5 & 24.9 & 19.8 & 22.8 & 13.8 & 13.1 & 20.7 & 23.6 & 12.7 & 25.3 & 29.0 & 26.6 & 28.3 & 19.5 \\
\hline dec & 22.0 & 9.8 & 14.3 & 7.4 & 20.7 & 25.6 & 19.7 & 21.8 & 10.3 & 19.7 & 15.7 & 20.4 & 32.5 & 30.2 & 27.6 & 15.5 & 19.6 \\
\hline Avg. & 17.7 & 12.9 & 13.1 & 11.9 & 19.1 & 22.3 & 24.0 & 18.5 & 16.5 & 20.2 & 20.4 & 18.7 & 23.6 & 22.4 & 25.1 & 20.9 & 19.2 \\
\hline
\end{tabular}


Potentially Collusive Observations at MW(+50c) Within First Quartile of Hourly Wages, "Cause" Measure

Subset of States Federeal MW

\begin{tabular}{crrrrrrrrrrrrrrrrrr}
\hline & 1990 & 1991 & 1992 & 1993 & 1994 & 1995 & 1996 & 1997 & 1998 & 1999 & 2000 & 2001 & 2002 & 2003 & 2004 & 2005 & Avg. \\
\hline jan & 5.7 & 7.3 & 5.5 & 5.8 & 5.2 & 3.9 & 4.8 & 5.2 & 5.8 & 4.4 & 2.0 & 2.4 & 2.6 & 1.6 & 2.3 & 2.8 & 4.2 \\
feb & 5.4 & 3.5 & 4.3 & 4.4 & 7.3 & 5.9 & 4.9 & 6.8 & 5.4 & 4.6 & 3.9 & 2.6 & 3.3 & 3.4 & 2.6 & 2.4 & 4.4 \\
mar & 3.9 & 4.8 & 3.8 & 3.5 & 4.8 & 3.6 & 5.7 & 8.3 & 5.1 & 3.4 & 4.5 & 2.5 & 2.8 & 2.9 & 2.1 & 1.9 & 4.0 \\
apr & 6.6 & 5.4 & 3.7 & 3.4 & 4.8 & 3.9 & 4.4 & 5.0 & 5.4 & 3.7 & 2.2 & 2.9 & 1.5 & 2.5 & 3.2 & 2.7 & 3.8 \\
may & 6.2 & 4.7 & 6.7 & 4.2 & 5.0 & 4.7 & 2.4 & 6.2 & 5.4 & 4.8 & 4.0 & 2.6 & 1.9 & 2.1 & 2.8 & 1.9 & 4.1 \\
jun & 6.2 & 4.5 & 4.3 & 4.2 & 4.6 & 5.2 & 3.4 & 7.9 & 4.7 & 3.9 & 4.3 & 2.6 & 3.3 & 2.3 & 2.4 & 2.8 & 4.2 \\
jul & 5.2 & 3.1 & 3.9 & 3.4 & 4.1 & 1.9 & 5.2 & 7.7 & 4.3 & 6.9 & 3.8 & 1.8 & 2.3 & 2.6 & 1.6 & 2.2 & 3.8 \\
aug & 4.4 & 4.5 & 3.1 & 3.0 & 7.4 & 4.8 & 4.2 & 5.8 & 4.5 & 1.7 & 2.2 & 2.9 & 2.5 & 3.1 & 2.6 & 1.9 & 3.6 \\
sep & 5.3 & 4.3 & 3.6 & 3.2 & 3.1 & 3.0 & 2.9 & 3.6 & 6.2 & 3.1 & 2.1 & 2.1 & 2.5 & 2.0 & 1.8 & 1.3 & 3.1 \\
oct & 4.5 & 3.9 & 3.9 & 2.8 & 4.1 & 3.9 & 6.6 & 4.2 & 3.6 & 2.9 & 1.9 & 2.3 & 2.8 & 2.5 & 3.8 & 2.4 & 3.5 \\
nov & 5.0 & 3.7 & 3.8 & 3.5 & 4.8 & 4.2 & 6.6 & 4.7 & 3.0 & 3.4 & 2.0 & 2.4 & 2.4 & 2.3 & 2.9 & 2.2 & 3.5 \\
dec & 5.3 & 4.8 & 3.4 & 3.0 & 3.9 & 4.7 & 4.4 & 4.1 & 3.2 & 3.6 & 1.9 & 1.8 & 2.8 & 1.5 & 2.9 & 2.1 & 3.3 \\
\hline Avg. & 5.3 & 4.5 & 4.1 & 3.7 & 4.9 & 4.2 & 4.6 & 5.8 & 4.7 & 3.9 & 2.9 & 2.4 & 2.5 & 2.4 & 2.6 & 2.2 & 3.8 \\
\hline
\end{tabular}

Subset of States with Own MW

\begin{tabular}{ccccccccccccccccccc}
\hline & 1990 & 1991 & 1992 & 1993 & 1994 & 1995 & 1996 & 1997 & 1998 & 1999 & 2000 & 2001 & 2002 & 2003 & 2004 & 2005 & Avg. \\
\hline jan & 2.8 & 1.8 & 4.7 & 2.3 & 3.9 & 3.9 & 2.5 & 4.2 & 4.7 & 6.4 & 2.8 & 4.0 & 3.0 & 1.5 & 2.7 & 3.0 & 3.4 \\
feb & 3.3 & 2.1 & 3.8 & 3.4 & 4.8 & 5.9 & 3.9 & 6.4 & 3.4 & 4.0 & 3.3 & 2.3 & 2.5 & 1.5 & 4.6 & 2.8 & 3.6 \\
mar & 4.3 & 3.1 & 3.1 & 2.7 & 4.0 & 3.6 & 4.9 & 4.4 & 4.5 & 3.7 & 5.0 & 2.1 & 4.2 & 3.7 & 3.2 & 3.2 & 3.7 \\
apr & 5.4 & 3.9 & 3.1 & 2.1 & 2.5 & 3.9 & 3.8 & 5.4 & 5.0 & 3.9 & 3.0 & 2.1 & 1.1 & 2.2 & 4.0 & 3.6 & 3.5 \\
may & 2.2 & 3.8 & 3.0 & 4.0 & 1.9 & 4.7 & 3.3 & 4.1 & 6.6 & 4.4 & 3.6 & 1.8 & 4.0 & 2.7 & 3.3 & 4.4 & 3.6 \\
jun & 4.1 & 2.6 & 2.5 & 2.6 & 4.5 & 5.2 & 3.7 & 9.1 & 4.7 & 4.2 & 4.6 & 2.7 & 3.2 & 2.8 & 3.5 & 3.2 & 4.0 \\
jul & 3.3 & 3.5 & 3.4 & 4.0 & 3.6 & 1.9 & 4.2 & 5.3 & 2.8 & 6.9 & 2.8 & 2.4 & 3.8 & 5.0 & 4.4 & 4.2 & 3.8 \\
aug & 2.0 & 3.0 & 4.7 & 2.4 & 4.2 & 4.8 & 5.0 & 6.3 & 5.4 & 3.2 & 4.1 & 2.8 & 3.2 & 3.3 & 2.9 & 4.1 & 3.8 \\
sep & 2.6 & 2.6 & 1.8 & 2.9 & 3.5 & 3.0 & 3.3 & 3.4 & 6.7 & 4.4 & 3.5 & 2.9 & 4.2 & 2.4 & 2.0 & 2.7 & 3.2 \\
oct & 3.5 & 2.7 & 3.3 & 3.0 & 4.0 & 3.9 & 5.8 & 3.3 & 3.6 & 3.9 & 3.1 & 2.8 & 5.2 & 3.3 & 2.9 & 2.4 & 3.5 \\
nov & 4.7 & 3.5 & 1.6 & 2.1 & 5.7 & 4.2 & 6.9 & 3.6 & 3.0 & 4.3 & 2.9 & 1.6 & 3.5 & 3.1 & 3.5 & 4.1 & 3.6 \\
dec & 4.4 & 2.8 & 3.4 & 1.6 & 4.8 & 4.7 & 7.3 & 5.2 & 2.4 & 3.7 & 2.6 & 2.5 & 4.5 & 3.8 & 3.6 & 2.5 & 3.7 \\
\hline Avg. & 3.6 & 2.9 & 3.2 & 2.8 & 3.9 & 4.2 & 4.5 & 5.1 & 4.4 & 4.4 & 3.4 & 2.5 & 3.5 & 2.9 & 3.4 & 3.3 & 3.6 \\
\hline
\end{tabular}

